\title{
Improving the Friction Durability of Magnetic Head-Disk Interfaces by Thin Lubricant Films
}

\author{
Shojiro Miyake, ${ }^{1}$ Shota Suzuki, ${ }^{1}$ and Masatoshi Miyake ${ }^{2}$ \\ ${ }^{1}$ Nippon Institute of Technology, 4-1 Gakuendai, Miyashiro-machi, Saitama 345-8501, Japan \\ ${ }^{2}$ Nishogakusha University, 6-16 Sanbancho, Chiyoda-ku, Tokyo 102-8336, Japan \\ Correspondence should be addressed to Shojiro Miyake; gosaburo@gmail.com
}

Received 30 January 2016; Accepted 1 June 2016

Academic Editor: Daniela Predoi

Copyright (c) 2016 Shojiro Miyake et al. This is an open access article distributed under the Creative Commons Attribution License, which permits unrestricted use, distribution, and reproduction in any medium, provided the original work is properly cited.

\begin{abstract}
Nanowear and viscoelasticity were evaluated to study the nanotribological properties of lubricant films of Z-tetraol, D-4OH, and $\mathrm{A} 20 \mathrm{H}$, including their retention and replenishment properties. For A20H and thick Z-tetraol-coated disks, the disk surface partially protrudes, and the phase lag $(\tan \delta)$ increases with friction. This result is consistent with replenishment of the lubricant upon tip sliding. For the D-4OH-coated disk, the $\tan \delta$ value decreases with tip sliding, similar to the case for the unlubricated disk. The durability of the lubricant-coated magnetic disks was then evaluated by load increase and decrease friction tests. The friction force of the unlubricated disk rapidly increases after approximately 30 reciprocating cycles, regardless of the load. The lubrication state can be estimated by mapping the dependence of friction coefficient on the reciprocating cycle number and load. The friction coefficient can be classified into one of four areas. The lowest friction area constitutes fluid lubrication. The second area constitutes the transition to mixed lubrication. The third area constitutes boundary lubrication. The highest friction of the fourth area results from surface fracture. The boundary lubricating area of the A20H lubricant was wide, because of its good retention and replenishment properties.
\end{abstract}

\section{Introduction}

Magnetic recording is accomplished by the motion of a magnetic head relative to a disk. Higher recording densities require that flying heights be as low as possible. High-bitcapacity magnetic disks require an extremely thin lubricant film on the disk surface, but thin lubricant films are prone to local damage during storage. This may lead to tribological problems at the head-disk interface and therefore problems with data reliability. Atomic scale wear and small friction fluctuations can degrade the performance of data storage devices $[1,2]$. Improving the tribological durability of magnetic disks is important for the magnetic recording industry. Methods for achieving extremely thin lubricants are therefore important for realizing more reliable magnetic storage devices [3].

The friction durability of the disk depends on the lubricants properties, such as its retention and replenishment [4]. Good retention enables the lubricant to stick firmly to the surface, which allows a high load-bearing capacity. Good replenishment enables the lubricant to reflow and cover areas depleted after sliding contact between the head and disk. The retention and replenishment of lubricants depend on their interactions with the diamond-like carbon (DLC) film on the surface of the disk $[5,6]$. Perfluoropolyether (PFPE) is a polymer consisting of carbon, oxygen, and fluorine. Functionalized PFPE lubricants have been investigated to improve the retention and replenishment of the lubricant on DLC films $[7,8]$.

Evaluating basic tribological properties on the nearatomic scale is becoming more important, because of the narrower head-disk separation and thinner lubricant layers employed in high-density recording. Lubricant films exhibit low vapor pressure, good viscosity, high thermal stability, and chemical inertness. These factors constitute attractive tribological properties for reducing friction and wear in rigid magnetic disks. These properties are dictated by the molecular structure of the lubricant, including its amounts and chemical states of carbon, fluorine, and oxygen. Polar hydroxyl groups of the lubricant provide good adhesion to the DLC film, while the hydrophobic PFPE backbone protects the DLC film [4-9]. 


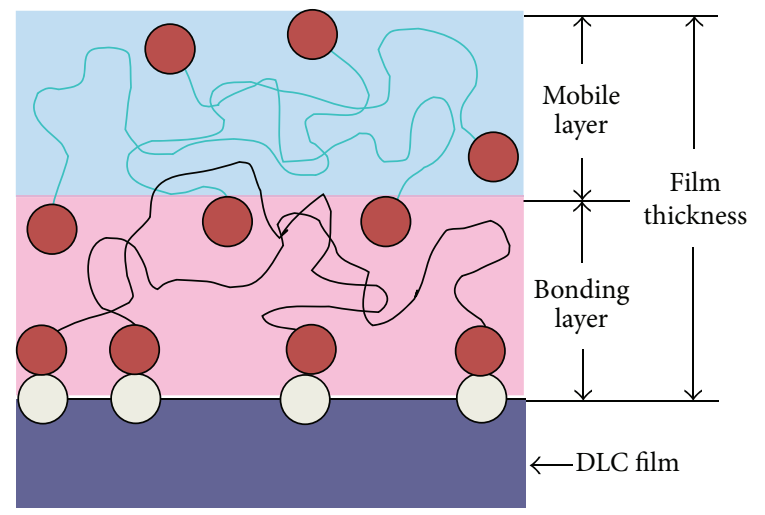

\begin{tabular}{lccc} 
Tested lubricants & & & \\
\hline & $\begin{array}{c}\text { Molecular } \\
\text { weight }\end{array}$ & $\begin{array}{c}\text { Film } \\
\text { thickness }(\mathrm{nm})\end{array}$ & $\begin{array}{c}\text { Bonding } \\
\text { layer (nm) }\end{array}$ \\
\hline DLC & - & 0 & 0 \\
Z-Tetraol (1.6 nm) & 2000 & 1.6 & 1.0 \\
Z-Tetraol (2.6 nm) & 2000 & 2.6 & 1.0 \\
D-4OH & 2000 & 1.6 & 1.0 \\
A20H & 5000 & 1.6 & 1.0 \\
\hline
\end{tabular}

Carbon
Polar group

Z-Tetraol $\mathrm{HOCH}_{2} \mathrm{CHCH}_{2} \mathrm{O}-\mathrm{CH}_{2}-\mathrm{CF}_{2} \mathrm{O}-\left[-\mathrm{CF}_{2} \mathrm{CF}_{2} \mathrm{O}-\right]-\left[-\mathrm{CF}_{2} \mathrm{O}-\right]-\mathrm{CF}_{2} \mathrm{CH}_{2}-\mathrm{OCH}_{2} \mathrm{CHCH}_{2} \mathrm{OH}$

$\mathrm{D}-4 \mathrm{OH}$

$\underset{\mathrm{OH}}{\mathrm{HOCH}_{2} \mathrm{CHCH}_{2} \mathrm{O}-\mathrm{CH}_{2}-\mathrm{CF}_{2} \mathrm{O}-\left[-\mathrm{CF}_{2} \mathrm{CF}_{2} \mathrm{CF}_{2} \mathrm{O}-\right]-\mathrm{CF}_{2} \mathrm{CH}_{2}-\mathrm{OCH}_{2} \mathrm{CHCH}_{2} \mathrm{OH}}$

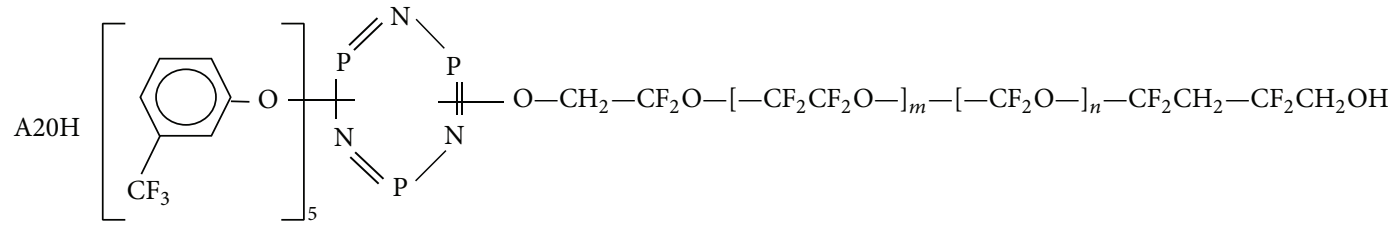

Figure 1: Model and molecular formula.

The durability of a magnetic disk upon sliding at the head-disk interface is affected by the disks wear properties. Decomposition mechanisms associated with contact sliding have been extensively studied. Understanding the dynamic behavior of lubricants on magnetic disks can clarify the lubrication mechanism at the head-disk interface. Scanning probe microscopies such as atomic force microscopy (AFM) have proven useful for this purpose [10-14]. The lubricating properties of lubricant-coated magnetic disks and dynamics of the lubricants behavior can be evaluated by force modulation AFM [10-12]. Deformation before and after nanowear testing and the state of the lubricant can also be evaluated $[13,14]$. Lateral force modulation friction testing can evaluate the effect of a lubricant's retention and replenishment on its nanowear properties.

In the current study, nanowear and viscoelastic evaluation tests were performed by AFM, to evaluate the behavior of three lubricants. The durability properties of these lubricants on coated magnetic disks were then investigated. The dependence of friction coefficient on load and reciprocating cycle number were investigated by load increase and decrease reciprocating friction tests. The friction coefficients were classified into four areas, and the dependence of lubricant behavior on durability was evaluated.

\section{Materials and Methods}

2.1. Lubricants. Four extremely thin lubricant-coated magnetic disks were used. The lubricants were Z-tetraol (Solvay Solexis Co.), D-4OH (Moresco Co.), and A20H (Moresco Co.) $[15,16]$. Their chemical formulas are shown in Figure 1. The thicknesses of these lubricant films were $1.6 \mathrm{~nm}$. However, $1.6 \mathrm{~nm}$ thick and $2.6 \mathrm{~nm}$ thick Z-tetraol lubricants were both tested, to clarify the effect of thickness on lubricant behavior. The thickness of the bonding layer of these lubricants is $\sim 1.0 \mathrm{~nm}$. The difference between the thicknesses of the lubricant and bonding layers corresponds to that of the free layer.

Z-Tetraol is based on a Fomblin Z-type backbone. It has high polarity because of two hydroxyl units at each end, and it strongly adsorbs to the DLC film. Z-Tetraol high polarity and flexible main chain mean that it readily coils into random coil shapes, which increases its molecular height.

$\mathrm{D}-4 \mathrm{OH}$ has a main chain with a repeating demnum backbone structure $\left(-\mathrm{CF}_{2} \mathrm{CF}_{2} \mathrm{CF}_{2} \mathrm{O}-\right)_{n}$ and two hydrogen radicals at each end. This arrangement realizes high adhesion with a low molecular height. Many terminal $\mathrm{OH}$ groups of $\mathrm{D}-4 \mathrm{OH}$ chains reside at the top of the film. $\mathrm{A} 20 \mathrm{H}$ has a phosphazene ring structure. The structure of $\mathrm{A} 20 \mathrm{H}$ is similar to that of Z-dol, except that one terminal group of Z-dol 


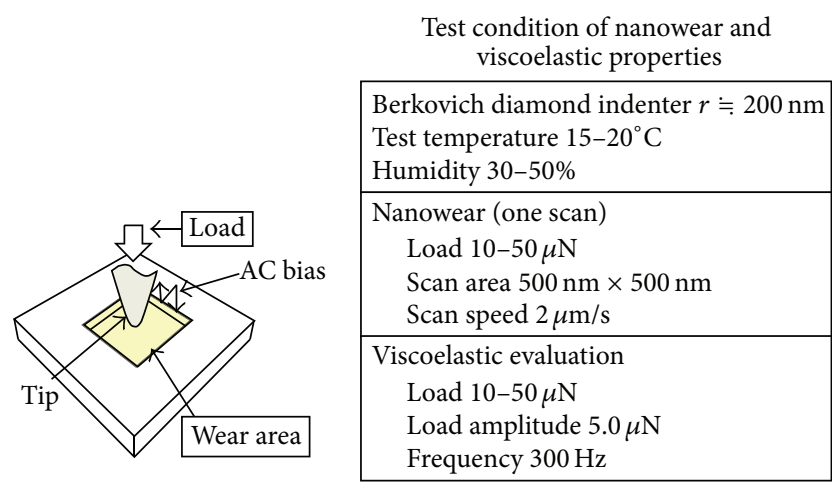

FIGURE 2: Method of force moderation test after nanowear test.

is replaced with a phosphazene unit. The terminal groups of $\mathrm{A} 20 \mathrm{H}$ possess phenoxy and p-methoxy-phenoxy units. Phenoxy groups of A20H spontaneously adsorb on the DLC film, because of interaction with the aromatic (graphitic) part of the DLC film. It follows that attaching a phenoxy group directly to the PFPE chain should result in its spontaneous adhesion to the DLC $[15,16]$.

2.2. Nanowear and Viscoelasticity Evaluation. The molecular motion of the lubricant on the DLC surface was investigated, because of its importance in wear and corrosion resistance. Nanowear tests of various lubricant-coated disks were performed using AFM, to evaluate the retention and replenishment of thin lubricant films. The AFM test setup is shown in Figure 2 [17]. The surface viscoelasticity of the lubricant film on the DLC layer was evaluated by dynamic force modulation (DFM), after the nanowear test. A Berkovich diamond indenter was used. It was shaped as an inverted three-sided pyramid, and its tip radius was $\sim 200 \mathrm{~nm}$. The wear test area was $500 \times 500 \mathrm{~nm}$, and the measured scan area was $1000 \times$ $1000 \mathrm{~nm}$. The wear depth was evaluated from the change in the profile and was used to evaluate the viscoelastic properties [18]. The indenter applied vibration in the vertical direction and was scanned across the tested surface. The phase lag $(\tan \delta)$ and displacement of the cantilever tip were calculated from the response of the tip indenter, which had a transducer controller. Viscoelastic properties including the storage modulus, loss modulus, and phase lag were determined. Tests were performed with under loads of $10-50 \mu \mathrm{N}$, an evaluation load of $5 \mu \mathrm{N}$, and a frequency of $300 \mathrm{~Hz}$.

2.3. Load Increase and Decrease Reciprocating Friction Tests. Load increase and decrease reciprocating friction tests were carried out to evaluate the tribological properties of the thin lubricant films. A friction tester (Shinto Scientific Co. Ltd. Heidon HHS2000) was used, as shown in Figure 3. The dependence of the friction coefficient on reciprocating cycle number was evaluated at each load, which was then used to evaluate the friction durability of the lubricant-coated disk. Plots of friction coefficient dependence on load and reciprocating cycle number were used to compare the behaviors of the lubricants. Tests were carried out under a $0-4 \mathrm{~N}$ load cycle that was repeated 500 times. The reciprocating distance was $10 \mathrm{~mm}$.

\section{Results and Discussions}

3.1. Nanowear Tests. Figures $4-8$ show the surface profiles and dependence of $\tan \delta$ on load, for samples with no lubricant, $1.6 \mathrm{~nm}$ thick Z-tetraol, $2.6 \mathrm{~nm}$ thick Z-tetraol, $1.6 \mathrm{~nm}$ thick $\mathrm{D}-4 \mathrm{OH}$, and $1.6 \mathrm{~nm}$ thick $\mathrm{A} 20 \mathrm{H}$ after nanowear tests. All samples exhibit protuberances and grooves. Protuberances are formed at the upper right side and grooves at the bottom left side. The lubricants on the surfaces are moved by friction. The maximum wear depths are all less than $1.6 \mathrm{~nm}$ (i.e., the lubricant film thickness). This indicates that these profiles are mainly formed by the movement of lubricant and plastic deformation. Figures 5, 6, and 7 show protuberances at the beginning of the wear test and grooves at the end, for the A20H, D-4OH, and $1.6 \mathrm{~nm}$ thick Z-tetraol samples, respectively. Figure 8 shows that the entire protuberance profile for the $2.6 \mathrm{~nm}$ thick Z-tetraol sample is like a gently sloping hill. The $\tan \delta$ value can be obtained by dividing the loss modulus by the storage modulus. A high $\tan \delta$ value means that the lubricant on the surface increases in viscosity. The state of the lubricant can therefore be evaluated from its profile and $\tan \delta$ distribution.

Figure 4 shows that the sample without lubricant primarily contains a wear groove on the magnetic disk. The change in the $\tan \delta$ value of the test without lubricant is similar to those of the lubricant-coated disks, because of the adsorbed layer on the DLC film. However, the adsorption layer is readily removed by friction, at which point $\tan \delta$ quickly decreases. The different behavior of the Z-tetraol films of different thicknesses is shown in Figures 5 and 6 . Under a load of $10 \mu \mathrm{N}$, the $\tan \delta$ value of the $2.6 \mathrm{~nm}$ thick Z-tetraol film increases, while the $\tan \delta$ value of the $1.6 \mathrm{~nm}$ thick Ztetraol film changes a little. The former contains a thick layer of free lubricant, and this layer is quickly restored following movement of the lubricant by friction.

For the $\mathrm{A} 20 \mathrm{H}$ lubricant, the $\tan \delta$ value also increases with friction. For the $2.6 \mathrm{~nm}$ thick Z-tetraol and $\mathrm{A} 20 \mathrm{H}$ samples, the $\tan \delta$ values of areas containing protuberances and wear grooves increase, compared to areas not subject to friction. This is shown in Figures 6 and 8, respectively, and demonstrates that the lubricant is replenished in the nanowear area. The $\tan \delta$ value of the $1.6 \mathrm{~nm}$ thick Z-tetraol sample increases slightly, as shown in Figure 5. In contrast, the $\tan \delta$ value of the $\mathrm{D}-4 \mathrm{OH}$ sample decreases, as shown in Figure 7. This sample also exhibits the smallest $\tan \delta$ value for the protuberance area, among the four tested samples. These decreases in $\tan \delta$ values are similar to that of the unlubricated sample. This indicates that $\mathrm{D}-4 \mathrm{OH}$ is poorly replenishing and is readily removed by friction.

The maximum groove depths at loads of 10, 20, and $30 \mu \mathrm{N}$ are shown in Figure 9. The maximum groove depth for each sample is saturated at this loading. Only the sample without lubricant is appreciably worn at a load of $40 \mu \mathrm{N}$, because it is subjected to the adsorption of water, oxygen, and hydrocarbons. It is thought that the wear depth of all lubricant 


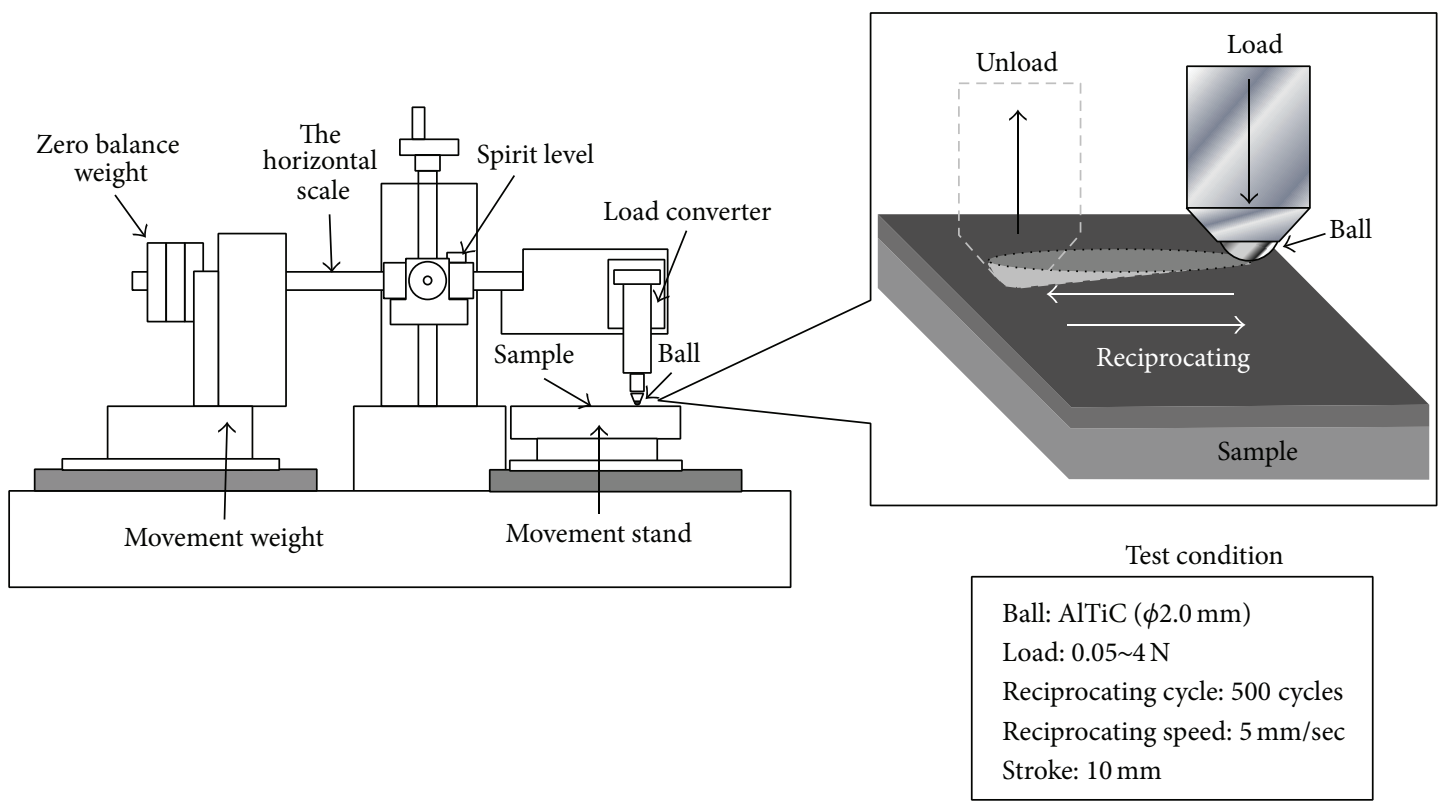

FIgURE 3: Load increase and decrease reciprocating friction test.

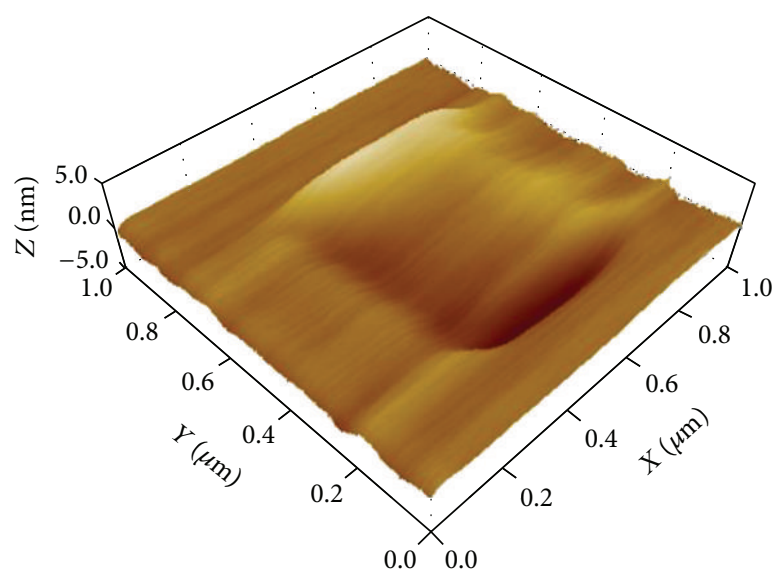

(a) $3 \mathrm{D}$ profile

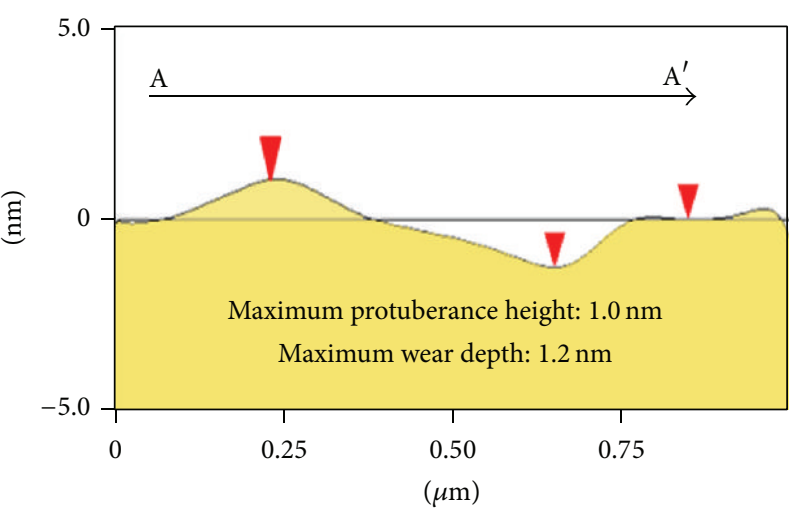

(c) Section profile

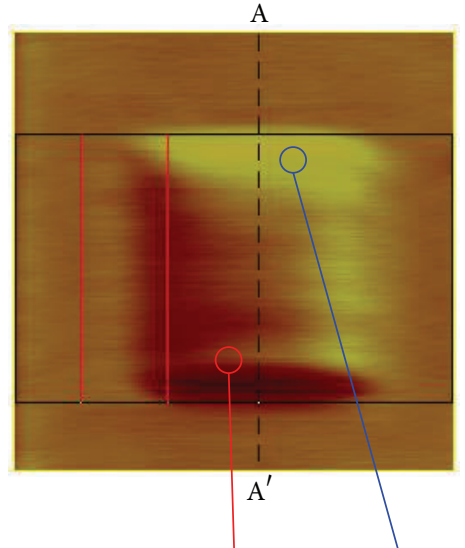

(b) 2D profile and measured sport

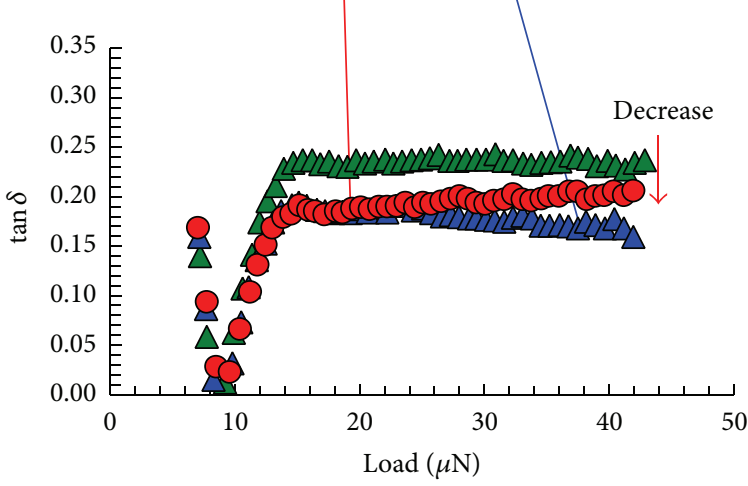
$\triangle$ Untested
- Groove
$\triangle$ Protuberance

(d) $\tan \delta$ of untested, protuberance, and groove

FIGURE 4: Surface properties of DLC film without lubricant after nanowear test. 


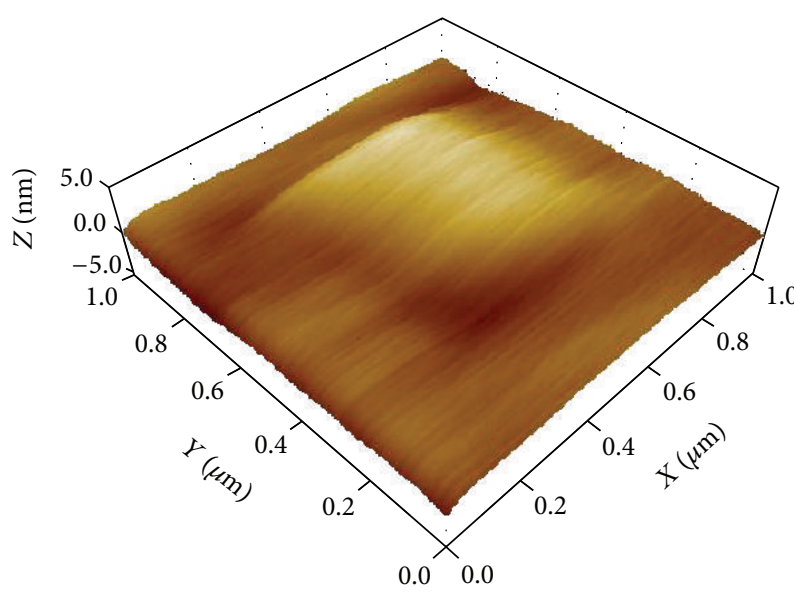

(a) 3D profile

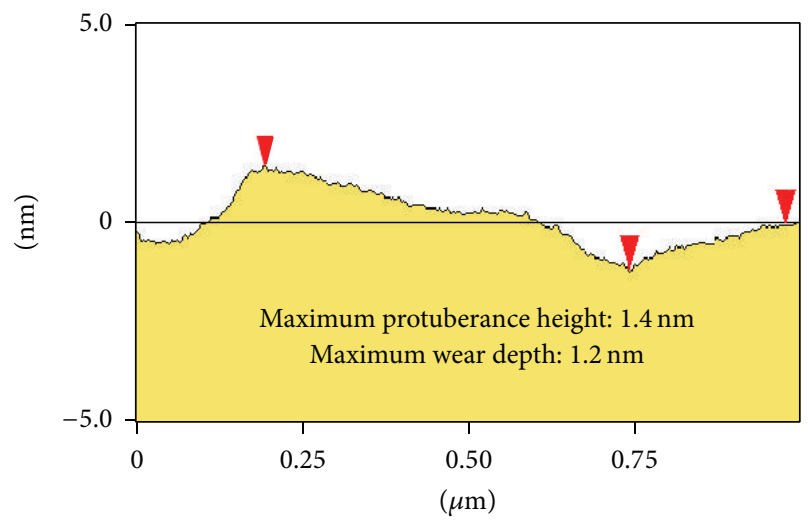

(c) Section profile

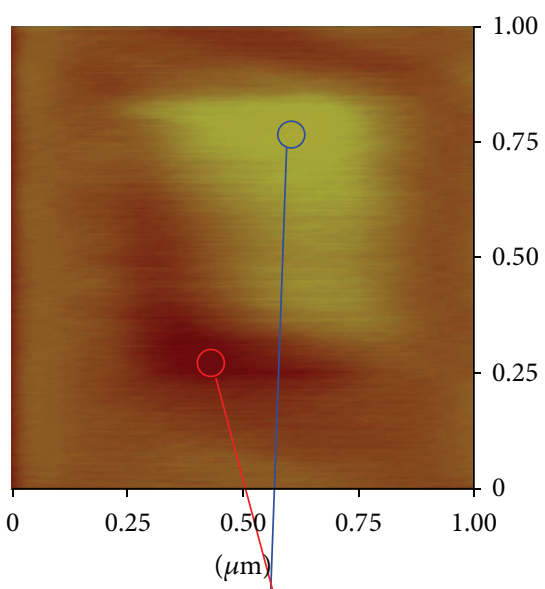

(b) 2D profile and measured sport

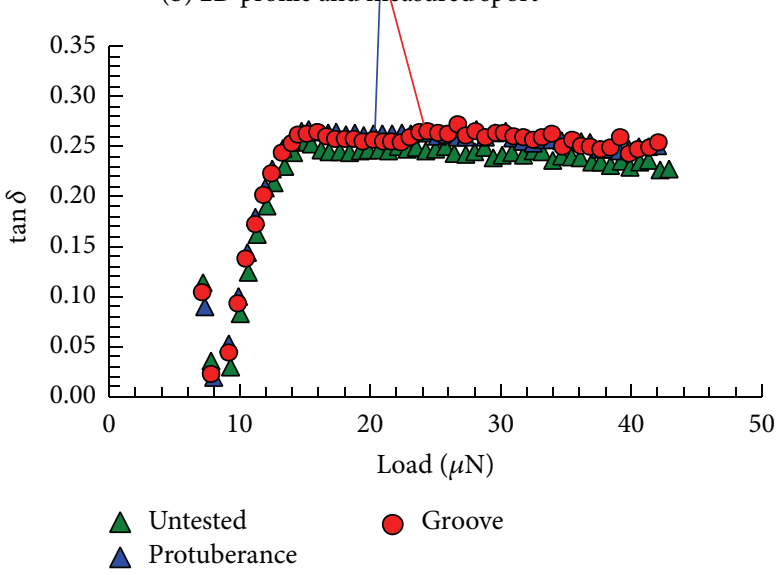

(d) $\tan \delta$ of untested, protuberance, and groove

FigURE 5: Surface properties of Z-tetraol $(1.6 \mathrm{~nm})$ after nanowear test.

layers decreases in the presence of the mobile lubricant and fixed layers on the DLC film.

At a load of $11 \mu \mathrm{N}$, the wear depths of the $1.6 \mathrm{~nm}$ thick Ztetraol and D-4OH samples are $\sim 0.6 \mathrm{~nm}$. The wear depths of the samples without lubricant and with $2.6 \mathrm{~nm}$ thick Ztetraol are $\sim 0.8 \mathrm{~nm}$. The wear depth of the $\mathrm{A} 20 \mathrm{H}$ sample $(0.4 \mathrm{~nm})$ is the smallest. This trend changes when the load increases to $20 \mu \mathrm{N}$. The $2.6 \mathrm{~nm}$ thick Z-tetraol sample has the smallest wear depth $(\sim 0.6 \mathrm{~nm})$. The wear depth at the left of the $2.6 \mathrm{~nm}$ thick Z-tetraol sample varies from 1.1 to $1.3 \mathrm{~nm}$. When the load increases to $30 \mu \mathrm{N}$, the $2.6 \mathrm{~nm}$ thick Z-tetraol sample exhibits the smallest wear depth of $\sim 0.8 \mathrm{~nm}$, and that of the A20H sample is $1.1 \mathrm{~nm}$. Loads of $40-50 \mu \mathrm{N}$ result in the $2.6 \mathrm{~nm}$ thick Z-tetraol sample exhibiting the smallest wear depth. Wear depth is influenced by the transformation of the mobile layer. This mobile layer is easily removed by friction and then replenishes the sliding area. The $2.6 \mathrm{~nm}$ thick Ztetraol sample exhibits good wear resistance, because its thick film readily replenishes the sliding area following friction. In contrast, replenishing by $1.6 \mathrm{~nm}$ thick Z-tetraol is poor, and that of the unlubricated disk is nonexistent, so these samples exhibit increased wear depths.
3.2. Friction Properties of Lubricants Evaluated by Load Increase and Decrease Reciprocating Testing. The dependence of friction force on reciprocating cycle number and load was then evaluated. The friction force of disks without lubricant and with $1.6 \mathrm{~nm}$ thick Z-tetraol, $2.6 \mathrm{~nm}$ thick Z-tetraol, D$4 \mathrm{OH}$, and $\mathrm{A} 20 \mathrm{H}$ is shown in Figures $10(\mathrm{a}), 10(\mathrm{~b}), 10(\mathrm{c})$, 10(d), and 10(e), respectively. Friction force increases with increasing load. In the absence of lubricant, the friction force rapidly increases early in the test, reaching a peak of $2.3 \mathrm{~N}$ after 27 reciprocating cycles at the maximum applied load of $4 \mathrm{~N}$, at which point it becomes saturated. The friction force of the $1.6 \mathrm{~nm}$ thick Z-tetraol sample increases from 72 cycles, reaching a peak at $2.2 \mathrm{~N}$ after 98 cycles. The friction force of the D-4OH sample increases from 184 cycles and reaches $2.3 \mathrm{~N}$ after 210 cycles. The friction force of the $2.6 \mathrm{~nm}$ thick Z-tetraol sample increases from 227 cycles and reaches $2.1 \mathrm{~N}$ after 265 cycles. Figure 10(e) shows that the A20H sample exhibits low friction for a large number of cycles. The friction force then increases after 393 cycles and reaches $2.3 \mathrm{~N}$ after 401 cycles. After the rapid increase in friction, the friction forces of all lubricant-coated disks increase to $\sim 2.0-2.3 \mathrm{~N}$ under a $4 \mathrm{~N}$ load, similar to the case without lubricant. 


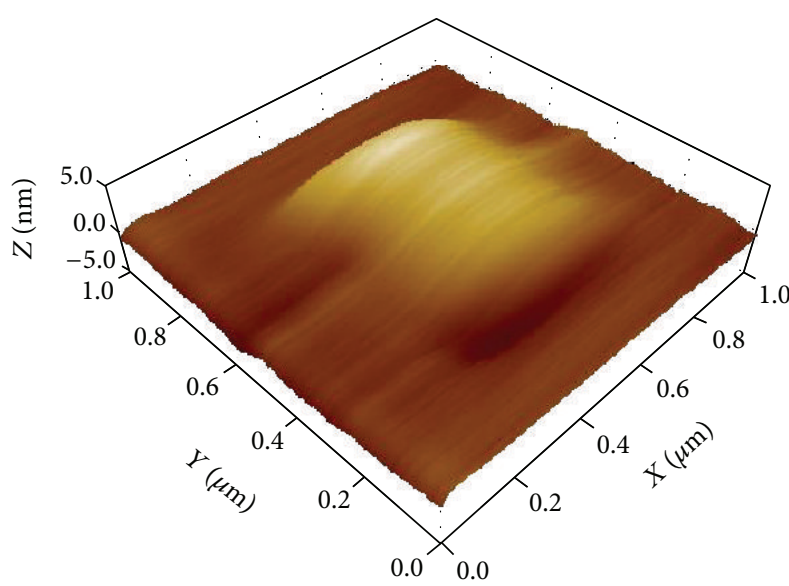

(a) $3 \mathrm{D}$ profile

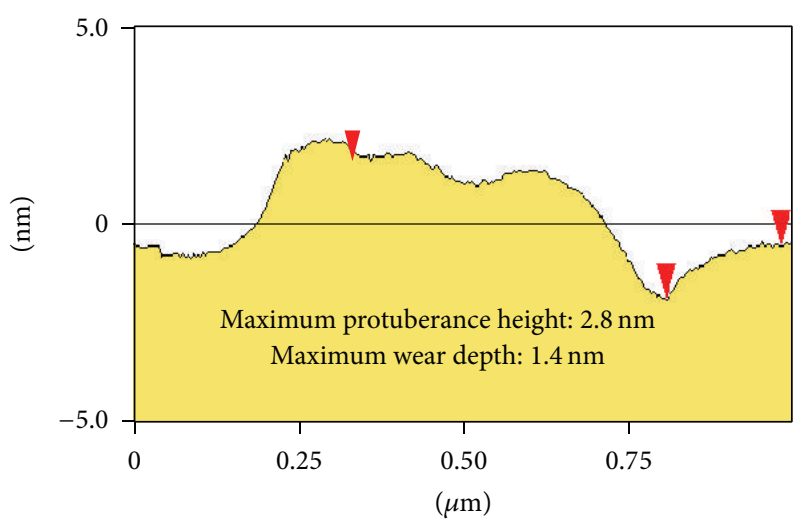

(c) Section profile

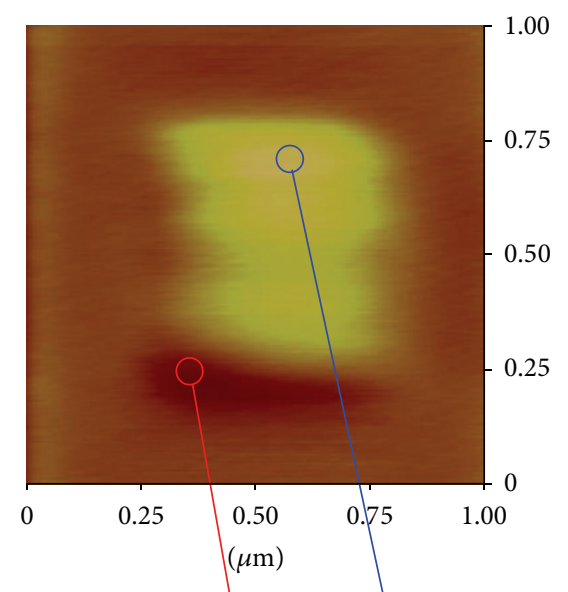

(b) $2 \mathrm{D}$ profile and measured sport

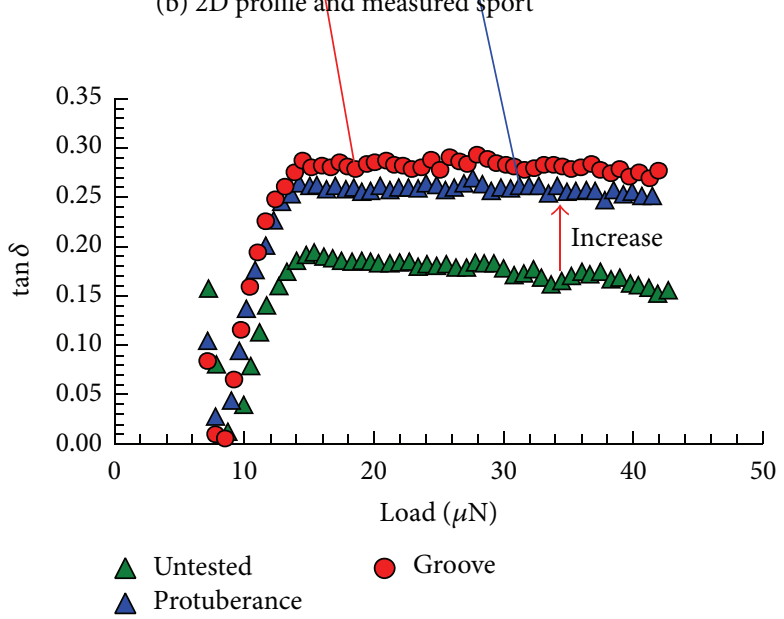

(d) $\tan \delta$ of untested, protuberance, and groove

FIGURE 6: Surface properties of Z-tetraol $(2.6 \mathrm{~nm})$ after nanowear test.

The changes in the friction coefficients of samples without lubricant and with $1.6 \mathrm{~nm}$ thick Z-tetraol, $2.6 \mathrm{~nm}$ thick Ztetraol, D-4OH, and A20H are shown in Figures 11(a), 11(b), 11(c), 11(d), and 11(e), respectively. The friction coefficients of the lubricant-coated disks are all low at early cycle numbers and then rapidly increase at a certain load and cycle number. The friction durability is determined by the number of reciprocating cycles and load.

Figure 12 shows the dependence of friction coefficient on reciprocating cycle number, at a load of $4 \mathrm{~N}$. The friction coefficient increases rapidly for each lubricant-coated disk. The A20H-coated disk exhibits the best friction durability.

\subsection{Evaluation of Lubricant Behavior from Changes in Friction} Coefficients. Figure 13 shows a detailed plot of the dependence of the friction coefficient on the load and number of reciprocating cycles, from which the endurance of the disk can be gauged. Figure 13(a) shows that the friction coefficient of the unlubricated DLC disk is largely constant with cycle number until 30 cycles, at which point it rapidly increases to $\sim 0.25$. The friction coefficient of the unlubricated disk is largely independent of the load, except at very low load.

At low load and cycle number, the friction coefficient of the $\mathrm{D}-4 \mathrm{OH}$ sample is lower than that without lubricant and then gradually increases with increasing load and cycle number. The friction coefficient plateaus before rapidly increasing. The friction coefficient increases with increasing load. The change in the friction coefficient as a consequence of the lubricant is clearly observed in Figure 13.

Figure 14 shows the different distributions of friction coefficients for the $1.6 \mathrm{~nm}$ thick and $2.6 \mathrm{~nm}$ thick Z-tetraol samples. The friction coefficient of the former is initially low and then increases rapidly. The latter exhibits lower friction coefficients at higher cycle numbers, before increasing rapidly.

The distribution of the friction coefficients of the $\mathrm{A} 20 \mathrm{H}$ sample is shown in Figure 15(a). A model of the friction coefficient transitions and lubricant behaviors are shown in Figure 15(b). The behavior of the lubricant can be estimated from the model of the friction coefficient transition. The boundary lines where the friction coefficient changes 


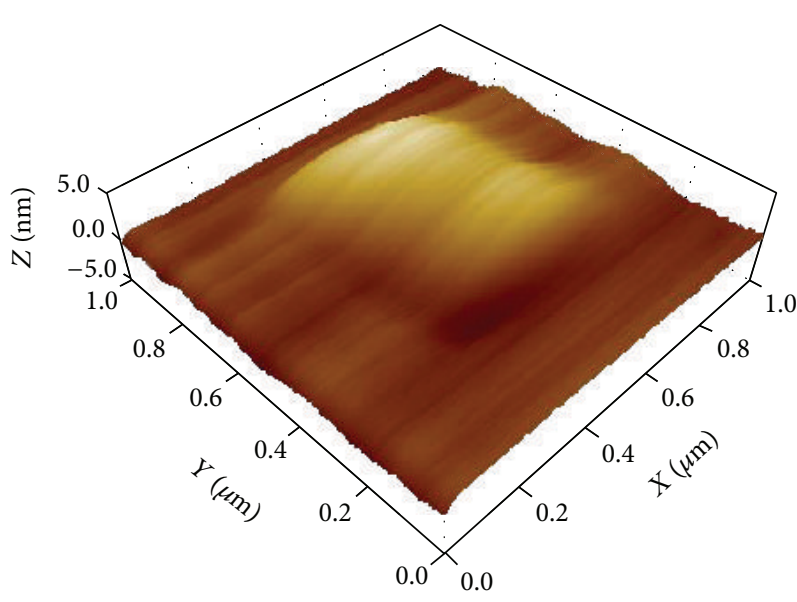

(a) 3D profile

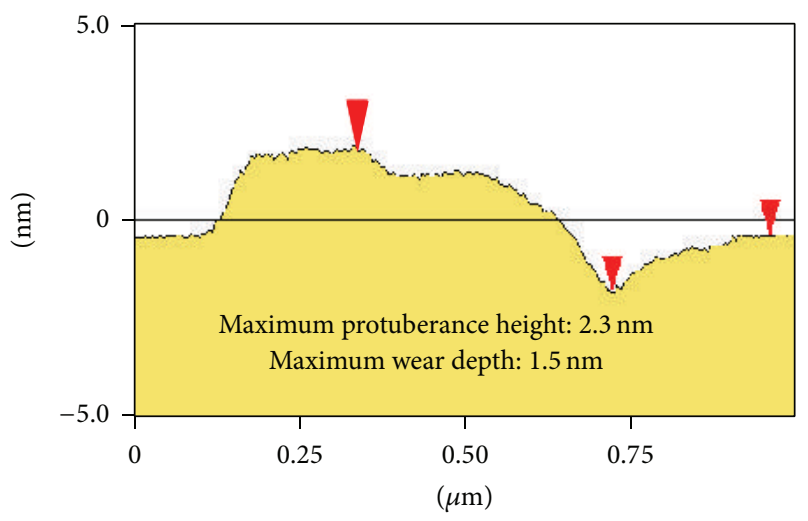

(c) Section profile

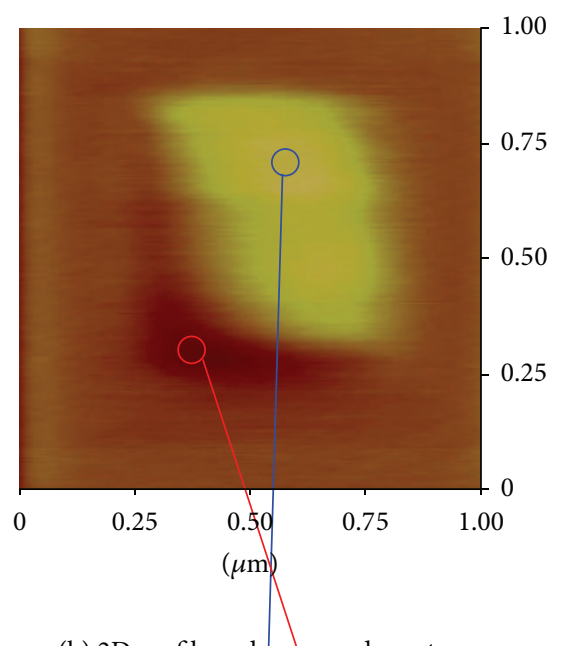

(b) $2 \mathrm{D}$ profile and measured sport

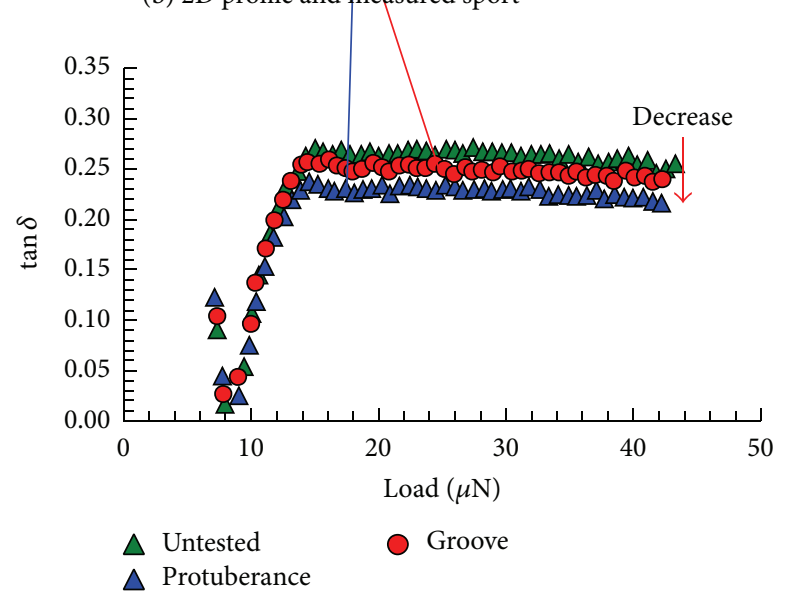

(d) $\tan \delta$ of untested, protuberance, and groove

FIGURE 7: Surface properties of D-4OH after nanowear test.

abruptly were then analyzed. The boundary lines (1), (2), and (3) shown in Figure 15(a) define four distinct areas (I, II, III, and IV). It is thought that line (1) represents the change in mobile layer of the main lubricant area. Line (2) represents the change from the transition area to the bonding layer and DLC thin film. Line (3) represents the change from the bonding layer and DLC, to the magnetic layer. The friction coefficient increases rapidly after line (3). SEM observations show that in this area (area IV) the DLC film is fractured and the magnetic layer is damaged. Line (3) therefore indicates the durability of the lubricant-coated disk. The effect of the cycle number of each lubricant varies with load, because of the lubricant effect. However, the friction coefficient of the unlubricated DLC increases rapidly with cycle number, regardless of load.

The friction coefficient dependence on load and cycle number is divided into four areas (I, II, III, and IV), by the three contour lines. These areas can be used to evaluate the lubricating state. Figure 16 shows a contour map of each lubricant. The behavior of the lubricant changes when the friction coefficient surpasses a boundary line. Table 1 shows the average, maximum, and minimum friction coefficients of each area, for each lubricant. The friction coefficients of the boundary lines for each lubricant are shown in Table 2. The friction coefficients can be classified into one of four areas. In area I, the friction coefficient is low because fluid lubrication by free lubricant is dominant. In area II, the friction coefficient transitions from fluid lubrication to boundary lubrication, which is defined as mixed lubrication. In area III, the friction coefficient is saturated. Boundary lubrication occurs from the fixed lubricant and the DLC film. In area IV, the friction coefficient is high because of the removal of the lubricant and DLC film.

Friction durability was evaluated from the boundary line (3) between areas III and IV. Figure 17 shows the values of the boundary lines for each lubricant. The A20H, $1.6 \mathrm{~nm}$ thick Z-tetraol, and $2.6 \mathrm{~nm}$ thick Z-tetraol samples exhibit similar trends. Cycle number is inversely proportional to load for boundary line (1). Boundary lines (2) and (3) show similar trends, but the rate of change with load is smaller. The cycle number of boundary line (3) decreases until $1.5 \mathrm{~N}$, at which point it becomes saturated. Boundary line (3) corresponds to a rapid increase in friction coefficient at a given cycle number. 


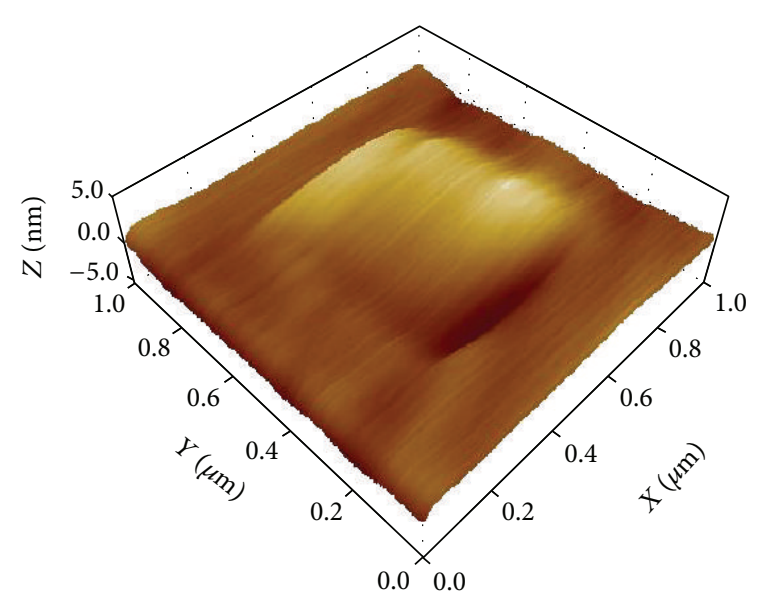

(a) 3D profile

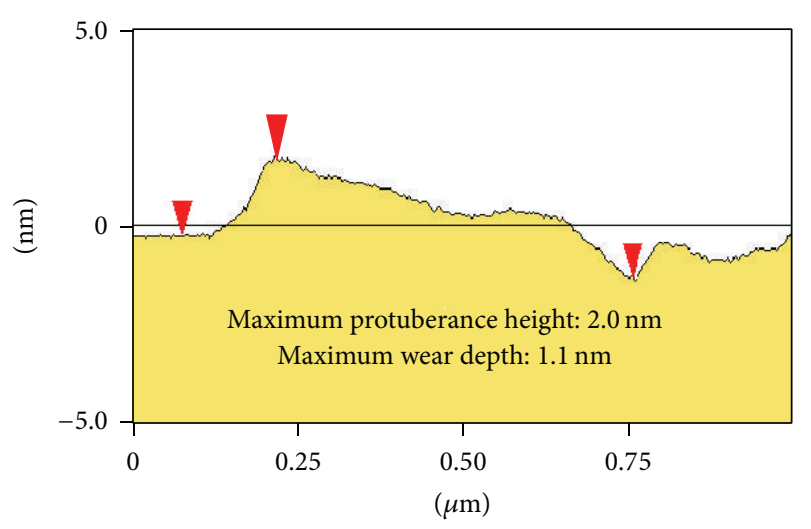

(c) Section profile

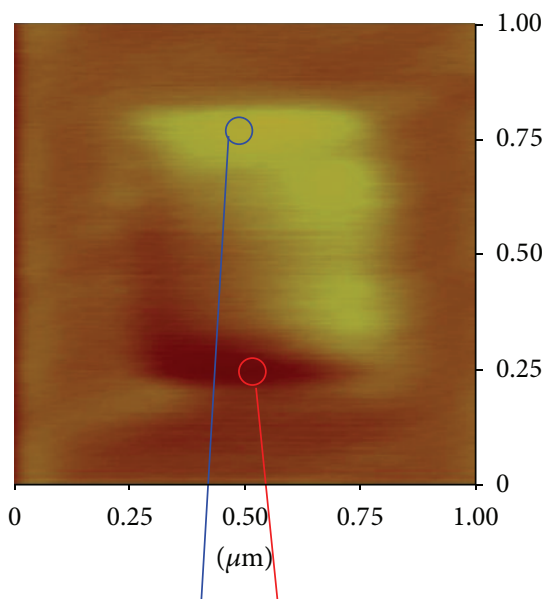

(b) $2 \mathrm{D}$ profile and measured sport

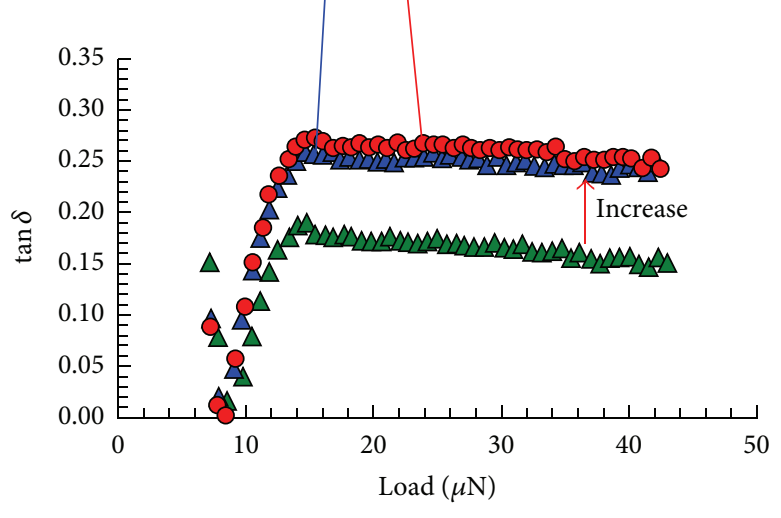

$\triangle$ Untested $\quad$ Groove

$\triangle$ Protuberance

(d) $\tan \delta$ of untested, protuberance, and groove

FIgURE 8: Surface properties of A20H after nanowear test.

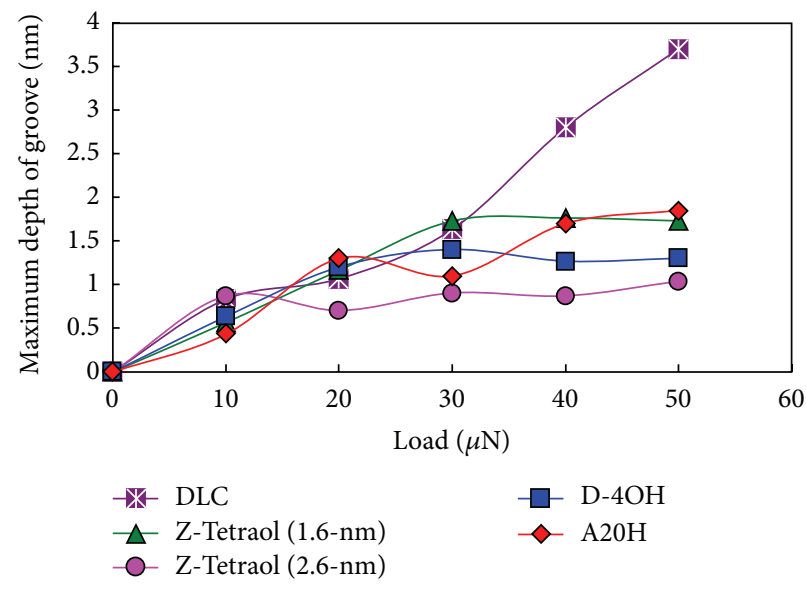

FIGURE 9: Nanowear depth of magnetic disks.

The rapid increase in the friction coefficient at line (3) corresponds to DLC fracture without lubricant, as shown in Figure 13(b).

For the $\mathrm{A} 20 \mathrm{H}$ sample, the cycle number is large for boundary line (1) under fluid lubrication by the mobile layer.
It changes from 90 cycles at $4 \mathrm{~N}$ to 390 cycles at $0.5 \mathrm{~N}$. For the A20H sample, the mobile layer greatly contributes towards durability. For the D-4OH and $1.6 \mathrm{~nm}$ thick Z-tetraol samples, line (1) changes from $\sim 10$ cycles at a $4 \mathrm{~N}$ load to $90-110$ cycles at $1 \mathrm{~N}$. The contribution of free lubrication is relatively small. 


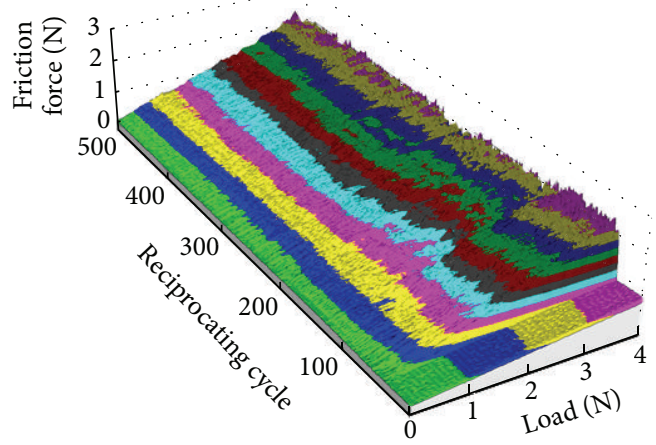

(a) DLC

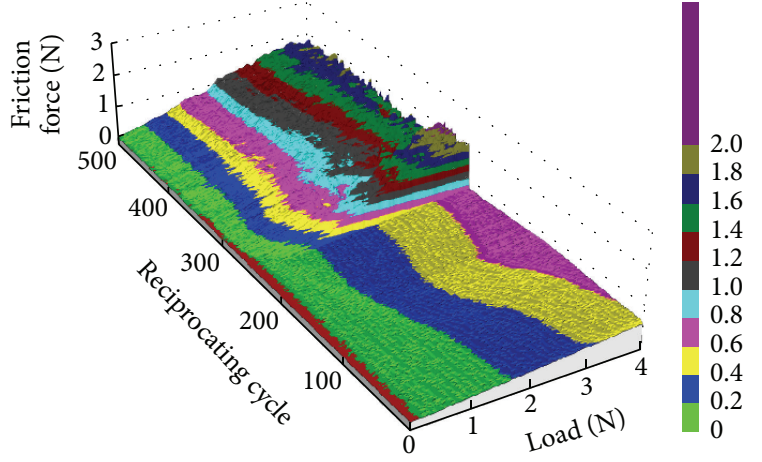

(c) Z-Tetraol $(2.6 \mathrm{~nm})$
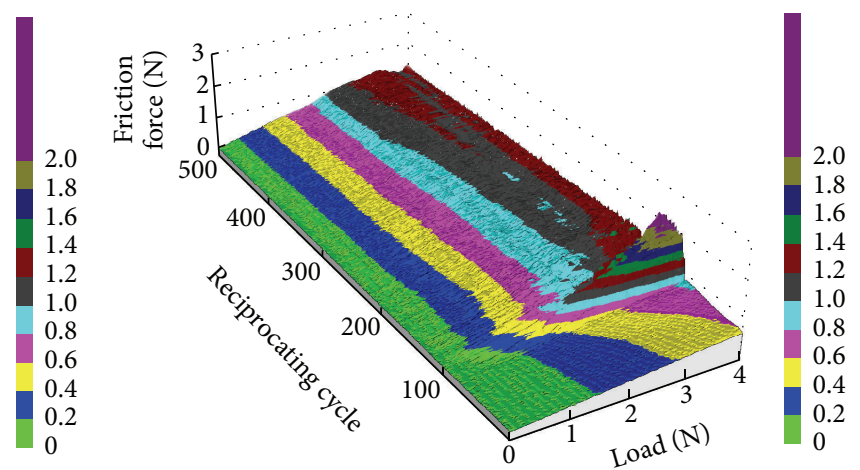

(b) Z-Tetraol $(1.6 \mathrm{~nm})$

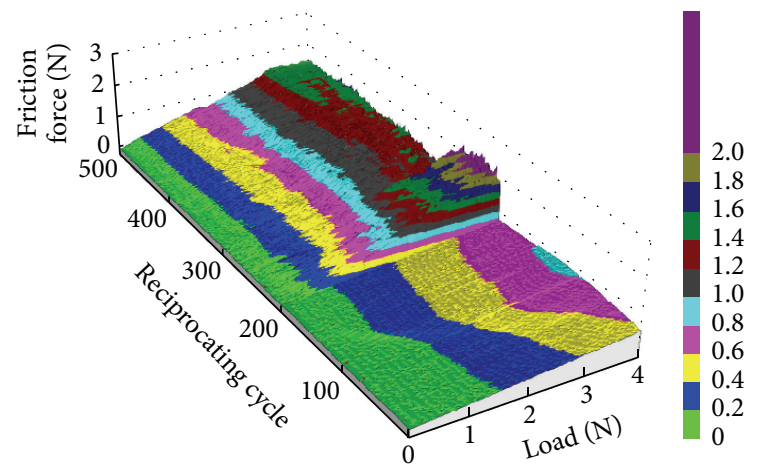

(d) $\mathrm{D}-4 \mathrm{OH}$

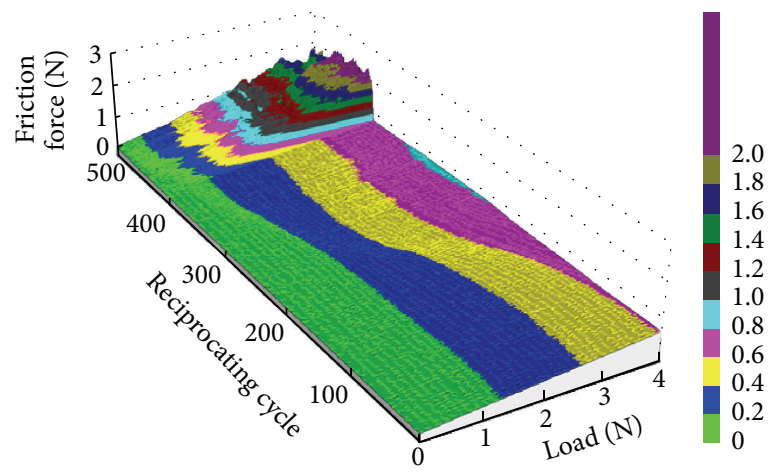

(e) $\mathrm{A} 20 \mathrm{H}$

FIGURE 10: Friction force of each magnetic disk.

TABLE 1: Average friction coefficient of each area.

\begin{tabular}{|c|c|c|c|c|}
\hline & $\begin{array}{c}\text { Average friction } \\
\text { coefficient of each area } \\
\text { I }\end{array}$ & $\begin{array}{c}\text { Average friction } \\
\text { coefficient of each area } \\
\text { II }\end{array}$ & $\begin{array}{c}\text { Average friction } \\
\text { coefficient of each area } \\
\text { III }\end{array}$ & $\begin{array}{c}\text { Average friction } \\
\text { coefficient of each area } \\
\text { IV }\end{array}$ \\
\hline DLC & - & - & - & 0.484 \\
\hline Z-Tetraol (1.6-nm) & 0.135 & 0.174 & - & 0.426 \\
\hline Z-Tetraol (2.6-nm) & 0.067 & 0.163 & 0.195 & 0.425 \\
\hline $\mathrm{D}-4 \mathrm{OH}$ & 0.116 & 0.170 & 0.214 & 0.445 \\
\hline $\mathrm{A} 20 \mathrm{H}$ & 0.136 & 0.176 & 0.216 & 0.431 \\
\hline
\end{tabular}




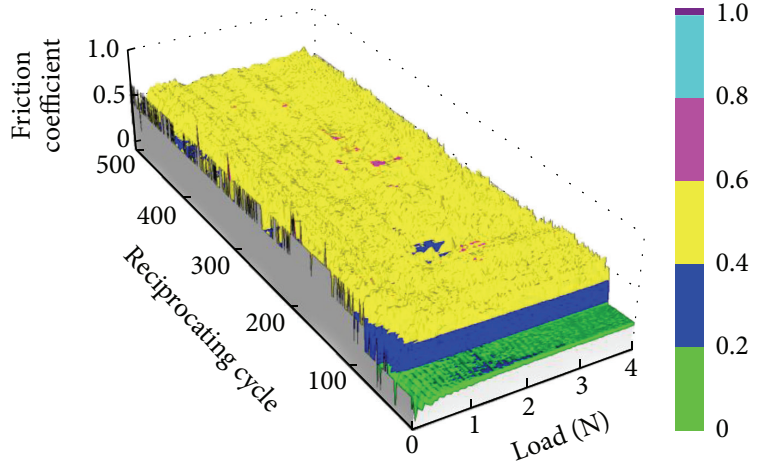

(a) DLC

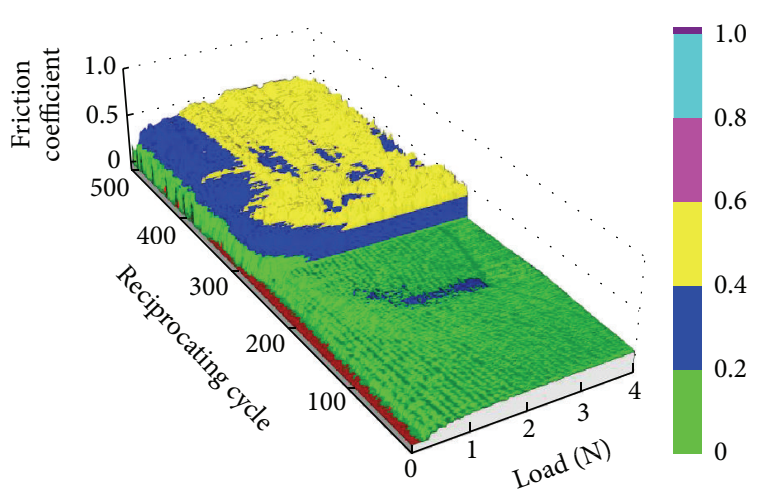

(c) Z-Tetraol $(2.6 \mathrm{~nm})$

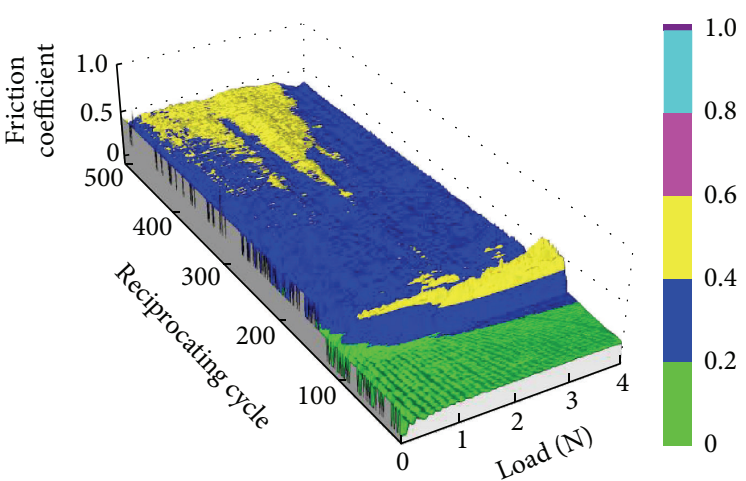

(b) Z-Tetraol $(1.6 \mathrm{~nm})$

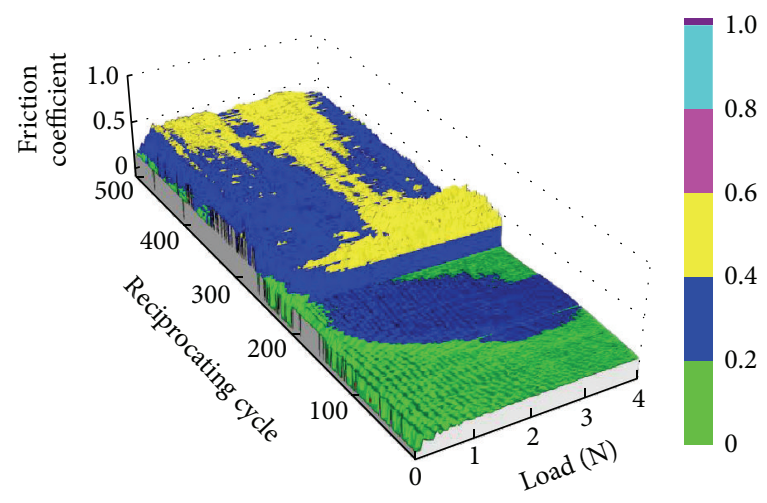

(d) $\mathrm{D}-4 \mathrm{OH}$

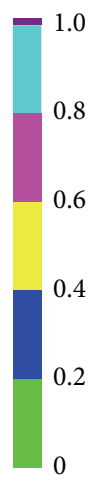

(e) $\mathrm{A} 20 \mathrm{H}$

Figure 11: Friction coefficient of each magnetic disk.

TABLE 2: Friction coefficient of each boundary line.

\begin{tabular}{lccc}
\hline & Boundary line (1) & Boundary line (2) & Boundary line (3) \\
\hline Z-Tetraol (1.6-nm) & 0.15 & 0.22 & 0.25 \\
Z-Tetraol (2.6-nm) & 0.14 & 0.17 & 0.25 \\
D-4OH & 0.15 & 0.20 & 0.25 \\
A20H & 0.16 & 0.20 & 0.25 \\
\hline
\end{tabular}

Figure 18 shows the difference in reciprocating cycles for each boundary line. These values correspond to the fluid lubrication area (area I), transition area (area II), and boundary lubrication area (area III). These areas are defined by line (1), line (2)-line (1), and line (3)-line (2), respectively. The
$2.6 \mathrm{~nm}$ thick Z-tetraol sample exhibits better durability than the $1.6 \mathrm{~nm}$ thick sample. The cycle number of the $1.6 \mathrm{~nm}$ thick Z-tetraol sample is low in the fluid lubrication, mixed lubrication, and boundary lubrication areas. The $2.6 \mathrm{~nm}$ thick Ztetraol sample exhibits a higher cycle number in the boundary 


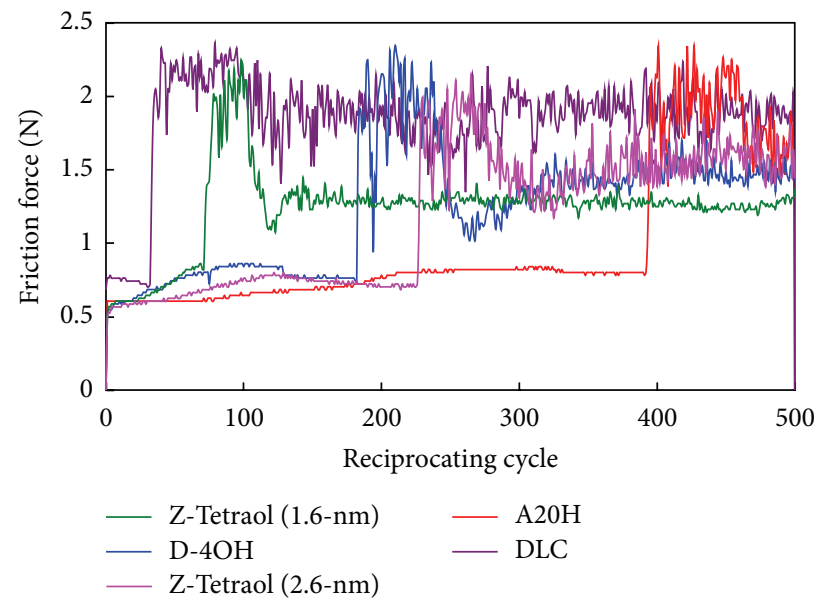

FIGURE 12: Critical reciprocating cycles (load $4 \mathrm{~N})$.

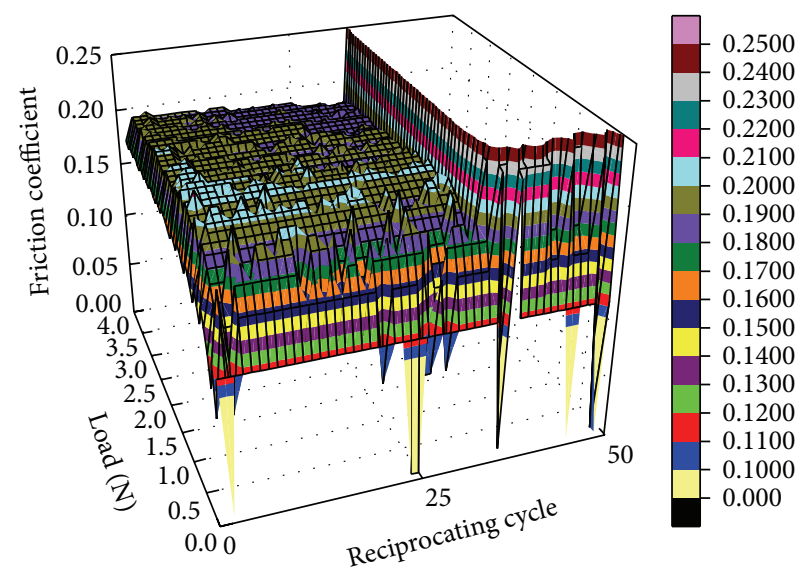

(a) DLC

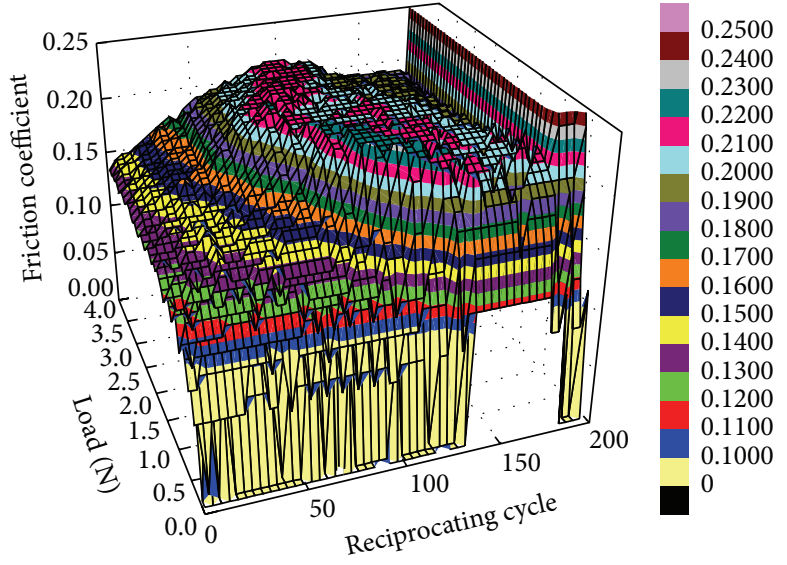

(b) $\mathrm{D}-4 \mathrm{OH}$

FIGURE 13: Precise change of friction coefficient dependence on load and reciprocating cycle without lubricant and with D-4OH.

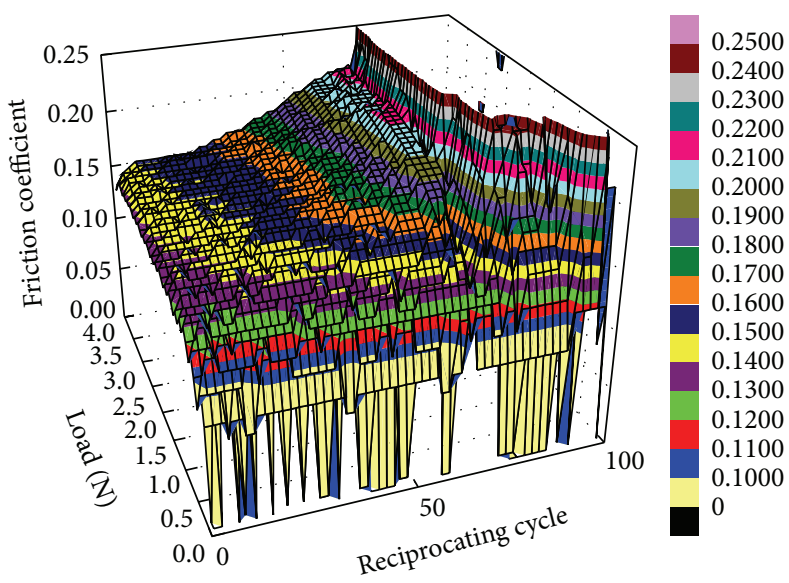

(a) Z-Tetraol $(1.6 \mathrm{~nm})$

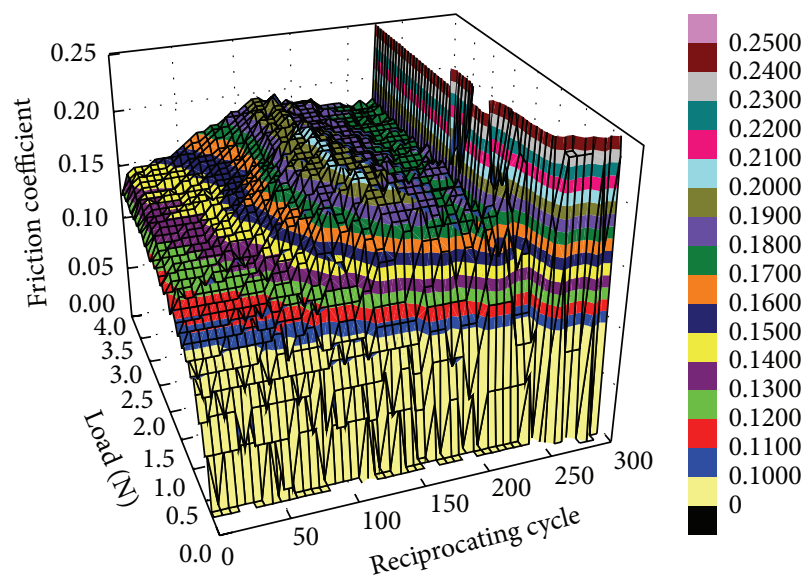

(b) Z-Tetraol $(2.6 \mathrm{~nm})$

FIGURE 14: Precise change of friction coefficient dependence on load and reciprocating cycle of Z-tetraol. 


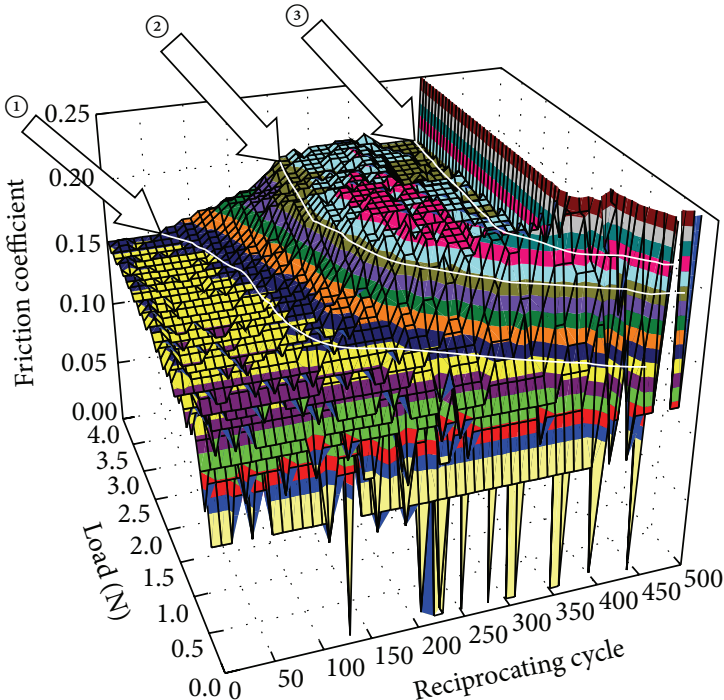

(a)

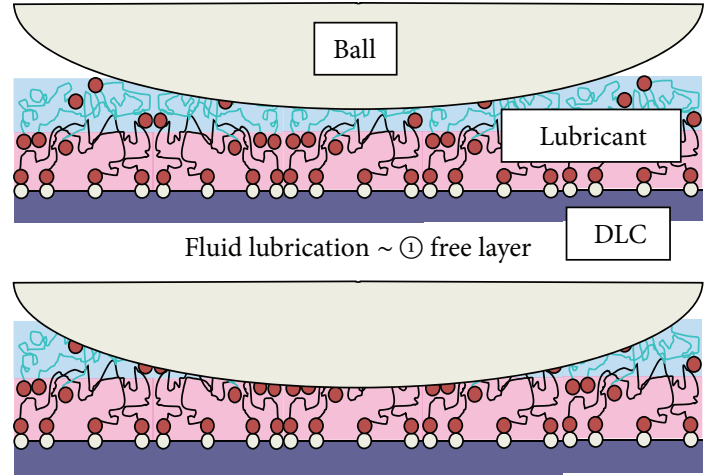

Mixed lubrication (trangent) (1) (2) free fix layer

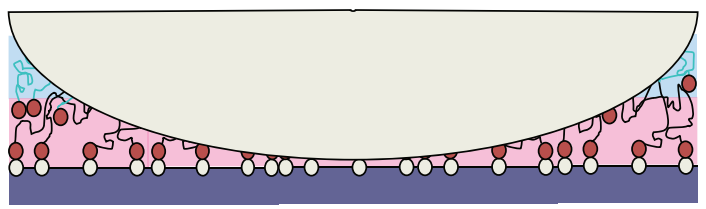

Boundary lubrication (2) (3) fix DLC layer

(b)

FIGURE 15: Friction coefficient of A20H and lubricant behavior.

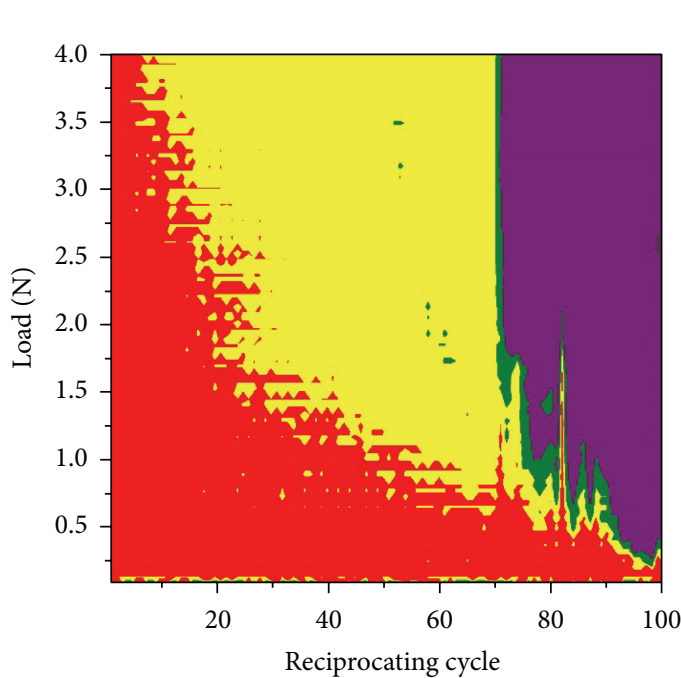

(a) Z-Tetraol $(1.6 \mathrm{~nm})$

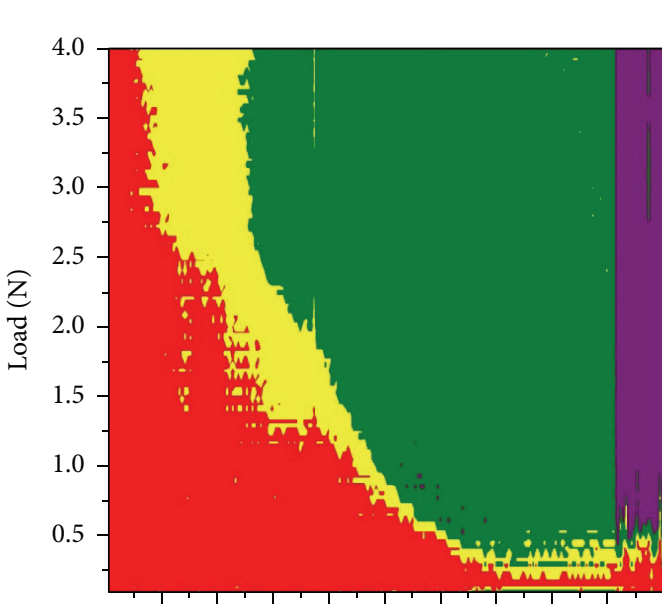

$\begin{array}{llllllllll}20 & 40 & 60 & 80 & 100 & 120 & 140 & 160 & 180 & 200\end{array}$ Reciprocating cycle

(c) $\mathrm{D}-4 \mathrm{OH}$
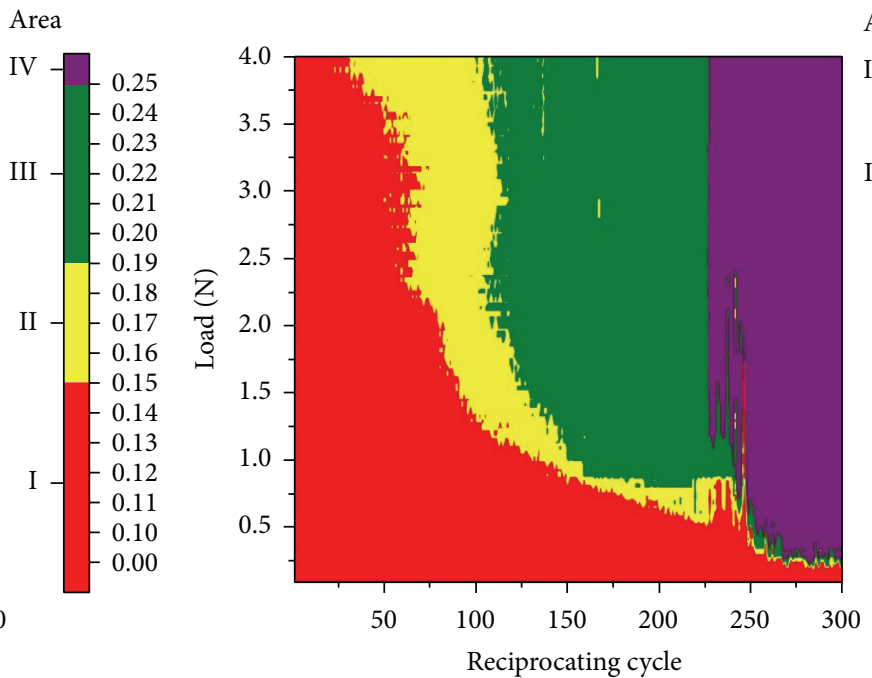

Area

(b) Z-Tetraol $(2.6 \mathrm{~nm})$

Area
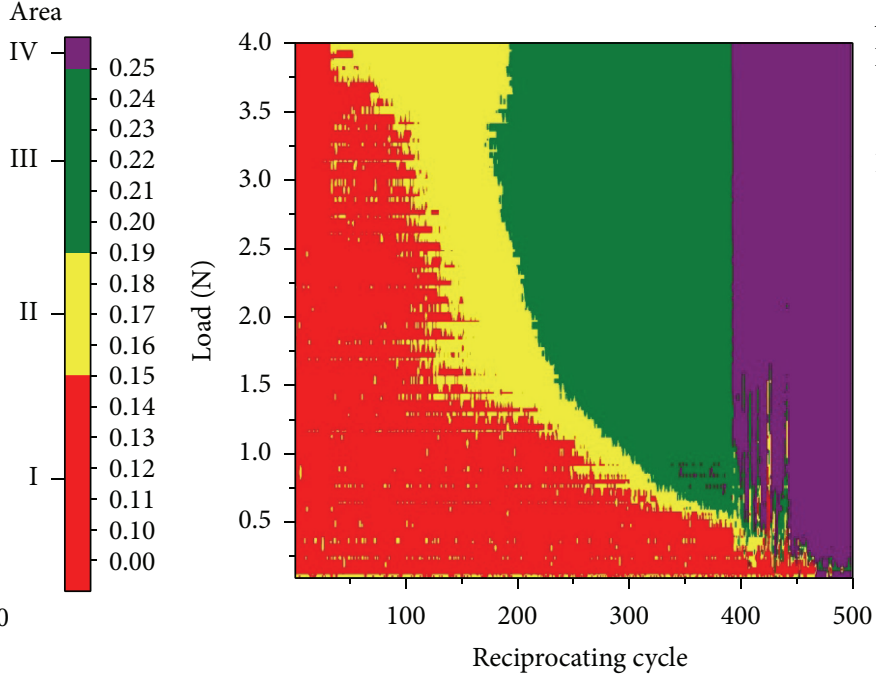

Area

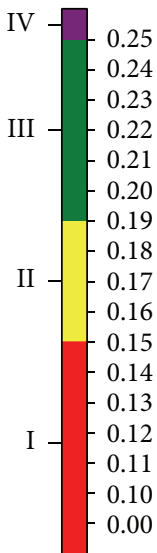

(d) $\mathrm{A} 20 \mathrm{H}$

FIGURE 16: Area analysis results of various lubricants. 


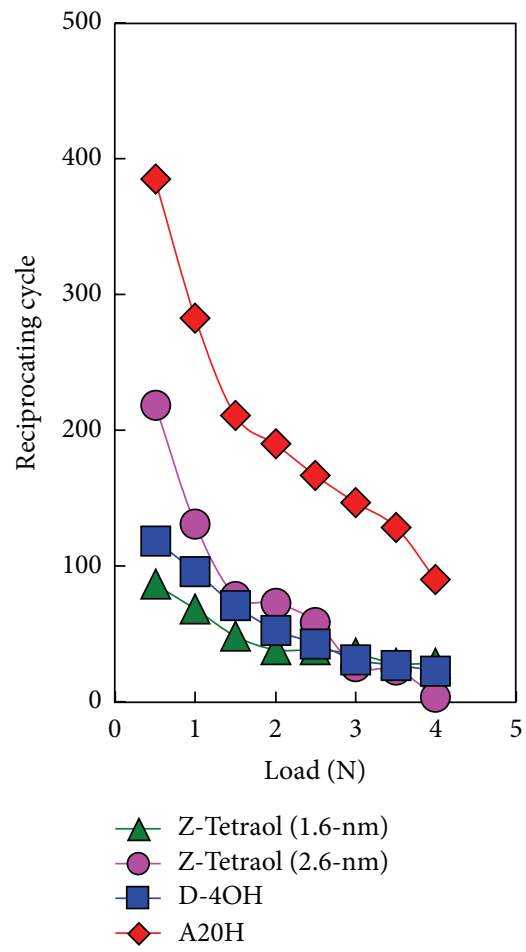

(a) Fluid lubrication

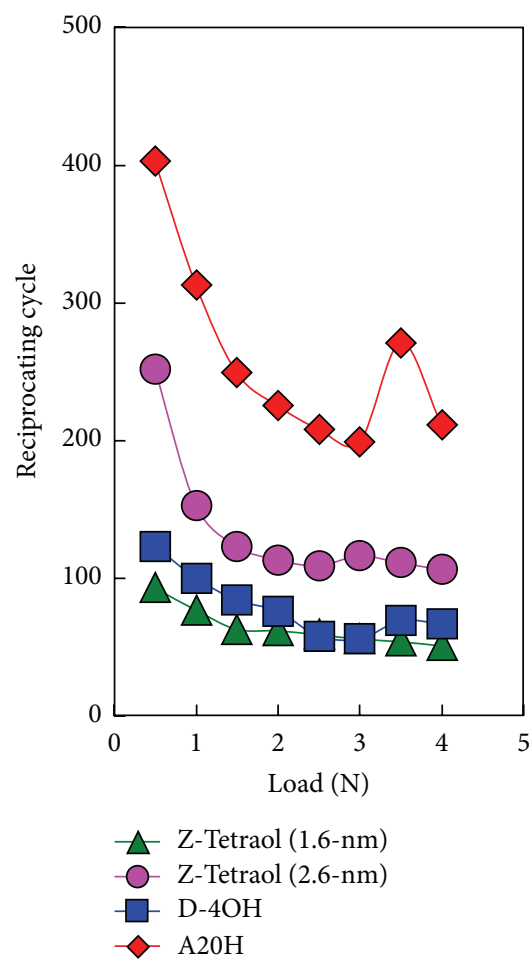

(b) Mixed lubrication

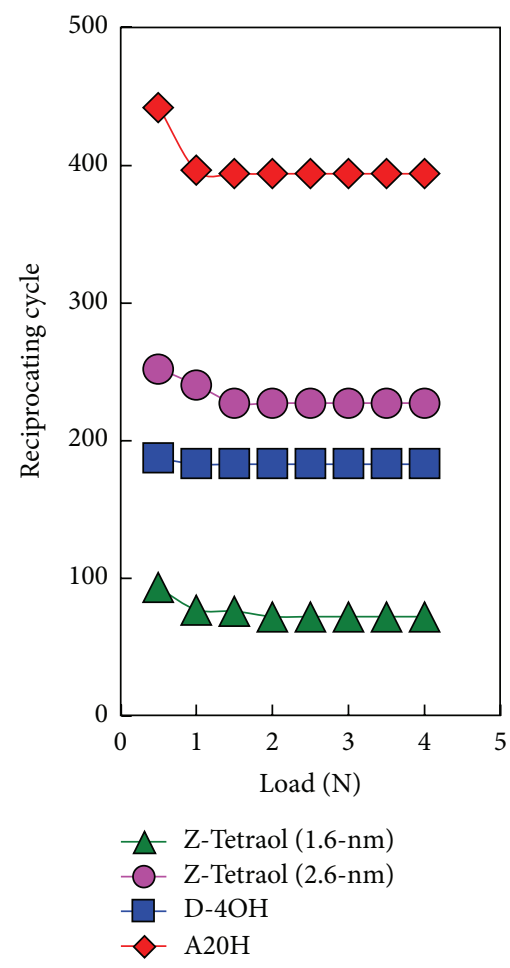

(c) Boundary lubrication

FIGURE 17: Relationship between reciprocating cycle and load at the boundary lines of friction coefficient of various lubricant-coated disks. (a) Boundary line (1) main and free, (b) boundary line (2) transition, and (c) boundary line (3) fixed-DLC layer.

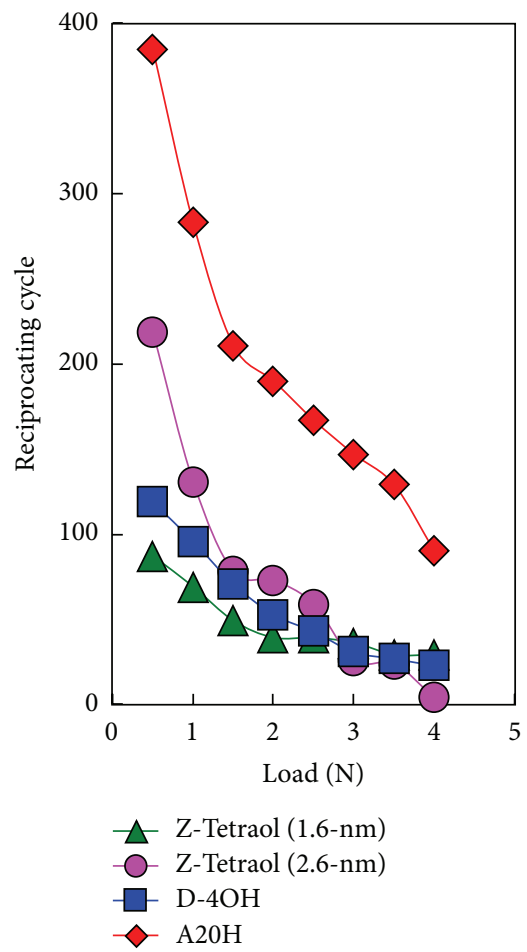

(a) Fluid lubrication

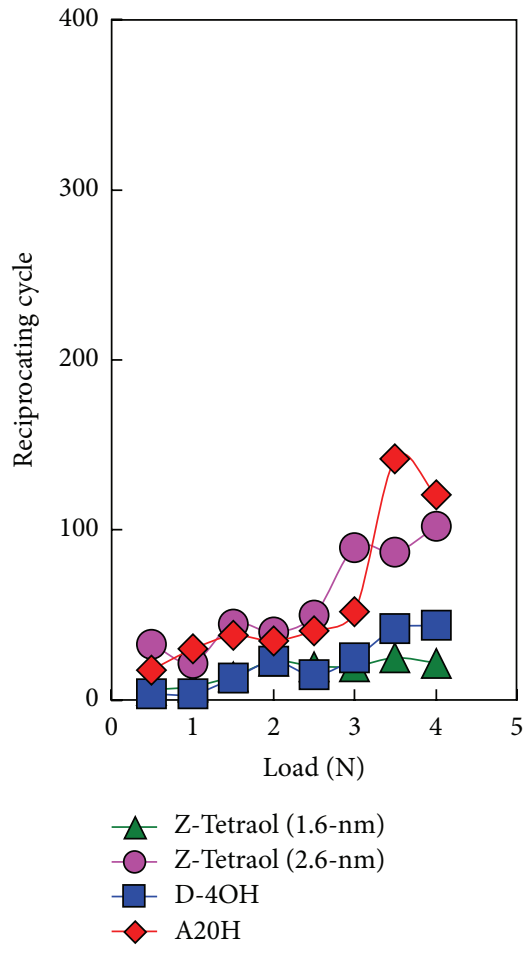

(b) Mixed lubrication

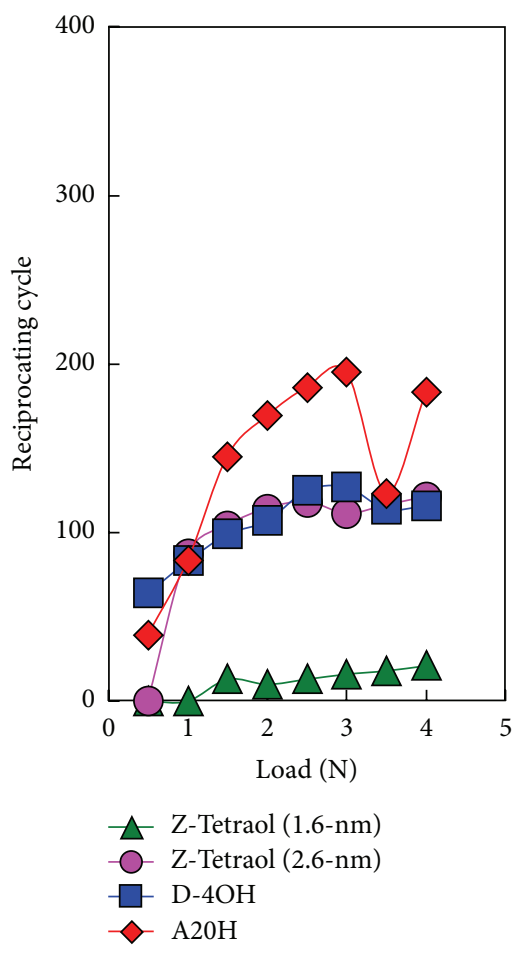

(c) Boundary lubrication

FIGURE 18: Areas of each cluster of friction coefficient of various lubricant-coated disks. (a) Boundary line (1) area I fluid lubrication, (b) boundary line (2)-(1) area mixed lubrication, and (c) boundary line (3)-(2) area boundary lubrication. 
lubrication area (area III) than that of the $1.6 \mathrm{~nm}$ thick Ztetraol sample. It can be deduced that free lubricant replenishes the friction area, and the state gradually changes from fluid lubrication to boundary lubrication.

The effect of the supply of free lubricant is small for the $\mathrm{D}-4 \mathrm{OH}$ sample. However, the boundary lubricant state is effective, and lubricant is retained until reaching a high load. This result is consistent with the previous nanowear results showing good retention of the $\mathrm{D}-4 \mathrm{OH}$ lubricant, despite its small replenishment. This suggests that the $\mathrm{D}-4 \mathrm{OH}$ lubricant has excellent adhesion and high stiffness, because of the properties of its main chain.

The $\mathrm{A} 20 \mathrm{H}$ sample exhibits the best friction durability. This is confirmed by the result that the change in friction coefficient varies from 400 cycles at $4 \mathrm{~N}$ to 450 cycles at $0.5 \mathrm{~N}$, as shown in Figure 17(c). It is thought that its excellent friction durability is because the fluid lubrication of the mobile layer (area I) and boundary lubrication (area III) are very wide. The A20H sample exhibits good durability, which is attributed to the action of the mobile layer and bonding layer, as shown in Figure 18.

The $2.6 \mathrm{~nm}$ thick Z-tetraol sample exhibits good wear resistance in the nanowear test. Macroscopic examination suggests that the durability of the $2.6 \mathrm{~nm}$ thick Z-tetraol sample is inferior to that of the $\mathrm{A} 20 \mathrm{H}$ sample. The difference between the macroscopic examination and nanowear test results reflects the test conditions. The AFM test involves a small $500 \times 500 \mathrm{~nm}$ sliding area, in which the lubricant is easily replenished. The thick free lubricant layer of the $2.6 \mathrm{~nm}$ thick Z-tetraol sample shows excellent nanowear resistance because of this replenishment.

\section{Conclusions}

Nanowear and viscoelastic evaluation tests were performed to study the retention and replenishment of lubricant films on magnetic disks. The durability and behavior of the lubricant films were then evaluated by load increase and decrease friction tests. The main conclusions are as follows:

(1) The $1.6 \mathrm{~nm}$ thick $\mathrm{A} 20 \mathrm{H}$ and $2.6 \mathrm{~nm}$ thick Z-tetraol samples exhibit excellent nanowear properties, and these lubricants are replenished following friction. The supply of lubricant to the friction area decreases the nanowear. In contrast, the $1.6 \mathrm{~nm}$ thick Z-tetraol and $\mathrm{D}-4 \mathrm{OH}$ lubricants are easily removed by sliding. The $\mathrm{D}-4 \mathrm{OH}$ lubricant exhibits poor replenishment but excellent retention.

(2) Changes in the friction coefficient with lubrication state can be estimated from friction coefficient maps. The map of the friction coefficient dependence on reciprocating cycle number and load can be divided by three boundary lines, and these three lines define four friction coefficient areas. Area I constitutes fluid lubrication by the mobile layer. Area II is transition to mixed lubrication. Area III is boundary lubrication. Area IV has a high friction coefficient because of fracture of the DLC surface.
(3) The rapid increase in the friction coefficient at certain cycle numbers and loads was evaluated. The friction durability is determined by these conditions. The $\mathrm{A} 20 \mathrm{H}$ and $2.6 \mathrm{~nm}$ thick Z-tetraol samples exhibit good durability, which is consistent with the nanowear results. The friction coefficients of the $\mathrm{A} 20 \mathrm{H}$ coated disk are stable, and its friction durability is superior to the samples. Areas I (fluid lubrication) and III (boundary lubrication) of the A20H sample are wide, because of its good retention and replenishment. The superior properties of the $\mathrm{A} 20 \mathrm{H}$ sample are consistent with AFM observations of the mobile and bonding layers.

\section{Competing Interests}

The authors declare that they have no competing interests.

\section{Acknowledgments}

This research was performed with the assistance of graduate students at the Nippon Institute of Technology, Japan, and was supported by the Storage Research Consortium (SRC).

\section{References}

[1] B. Bhushan, Tribology and Mechanics of Magnetic Storage Devices, Springer, New York, NY, USA, 1990.

[2] K. E. Johnson, C. M. Mate, J. A. Merz, R. L. White, and A. W. Wu, "Thin-film media-current and future technology," IBM Journal of Research and Development, vol. 40, no. 5, pp. 511-535, 1996.

[3] S. Miyake and M. Wang, "Nanotribology of magnetic disks," in Encyclopedia of Nanoscience and Nanotechnology, pp. 1-52, American Scientific Publishers, 2013.

[4] Y. Mitsuya, H. Zhang, J. Ohgi, and K. Fukuzawa, "Experimental comparisons of spreading and replenishment flows of molecularly thin lubricant films coated on magnetic disks," IEEE Transactions on Magnetics, vol. 44, no. 11, pp. 3641-3644, 2008.

[5] K. Fukuzawa, S. Terada, M. Shikida, H. Amakawa, H. Zhang, and Y. Mitsuya, "Dual-axis micromechanical probe for independent detection of lateral and vertical forces," Applied Physics Letters, vol. 89, no. 17, Article ID 173120, 3 pages, 2006.

[6] S. Itoh, K. Fukuzawa, Y. Hamamoto, and H. Zhang, "Temperature dependence of the viscoelastic properties of a confined liquid polymer measured by using an oscillating optical fiber probe," Japanese Journal of Applied Physics, vol. 49, no. 8, Article ID 08LB13, 5 pages, 2010.

[7] H. Tani, H. Kitagawa, and N. Tagawa, "Bonding mechanism of perfluoropolyether lubricant film with functional endgroup on magnetic disks by ultraviolet irradiation," Tribology Letters, vol. 45, no. 1, pp. 117-122, 2012.

[8] H. Tani, T. Shimizu, N. Kobayashi, Y. Taniike, K. Mori, and N. Tagawa, "Study of molecular conformation of PFPE lubricants with multidentate functional groups on magnetic disk surface by experiments and molecular dynamics simulations," IEEE Transactions on Magnetics, vol. 46, no. 6, pp. 1420-1423, 2010.

[9] Z. Tao and B. Bhushan, "Bonding, degradation, and environmental effects on novel perfluoropolyether lubricants," Wear, vol. 259, no. 7-12, pp. 1352-1361, 2005. 
[10] A. Kumagai, K. Harada, K. Ozawa, and O. Ishiwata, "Evaluation of tribological properties of a longitudinal magnetic recording medium using lateral modulation friction force microscope," Japanese Journal of Applied Physics, vol. 35, no. 12A, pp. 62866291, 1996.

[11] J. S. Jourdan, S. J. Cruchon-Dupeyrat, Y. Huan, P. K. Kuo, and G. Y. Liu, "Imaging nanoscopic elasticity of thin film materials by atomic force microscopy: effects of force modulation frequency and amplitude," Langmuir, vol. 15, no. 19, pp. 6495-6504, 1999.

[12] S. Miyake, Y. Takahashi, M. Wang, T. Saitoh, and S. Matsunuma, "Lubricant supply from crystal boundaries of perpendicular magnetic disk evaluated by lateral modulation friction force microscopy," Japanese Journal of Applied Physics, vol. 43, no. 11, Article ID L1469, 2004.

[13] S. Miyake, Y. Wakatsuki, M. Wang, and S. Matsunuma, "Amplitude dependence of the lateral-vibration wear test for perpendicular recording magnetic disks treated by heat curing," Japanese Journal of Applied Physics, vol. 44, no. 5, pp. 3209-3217, 2005.

[14] S. Miyake, S. Ninomiya, and M. Wang, "Lubricant state evaluation of ultraviolet-irradiated magnetic disk using lateral friction force modulation microscopy with electric current distribution," Japanese Journal of Applied Physics, vol. 44, no. 8-11, pp. L299-L302, 2005.

[15] P. H. Kasai and A. Wakabayashi, "Disk lubricant additives, A20H and C2: characteristics and chemistry in the disk environment," Tribology Letters, vol. 31, no. 1, pp. 25-35, 2008.

[16] D. Spaulding, Z. Yang, and J. J. Liu, "Dual layer X-ray photoelectron spectroscopy model to simultaneously determine a PFPE/A20H lubricant mixture and carbon-layer thicknesses on hard-disk magnetic media," IEEE Transactions on Magnetics, vol. 41, no. 10, pp. 3040-3042, 2005.

[17] T. Saitoh, S. Miyake, and S. Matsunuma, "Micro-tribological properties of heat treated hard disk evaluated by force modulation method," Microsystem Technologies, vol. 11, no. 8-10, pp. 1138-1145, 2005.

[18] S. A. S. Asif, K. J. Wahl, and R. J. Colton, "Nanoindentation and contact stiffness measurement using force modulation with a capacitive load-displacement transducer," Review of Scientific Instruments, vol. 70, no. 5, pp. 2408-2413, 1999. 

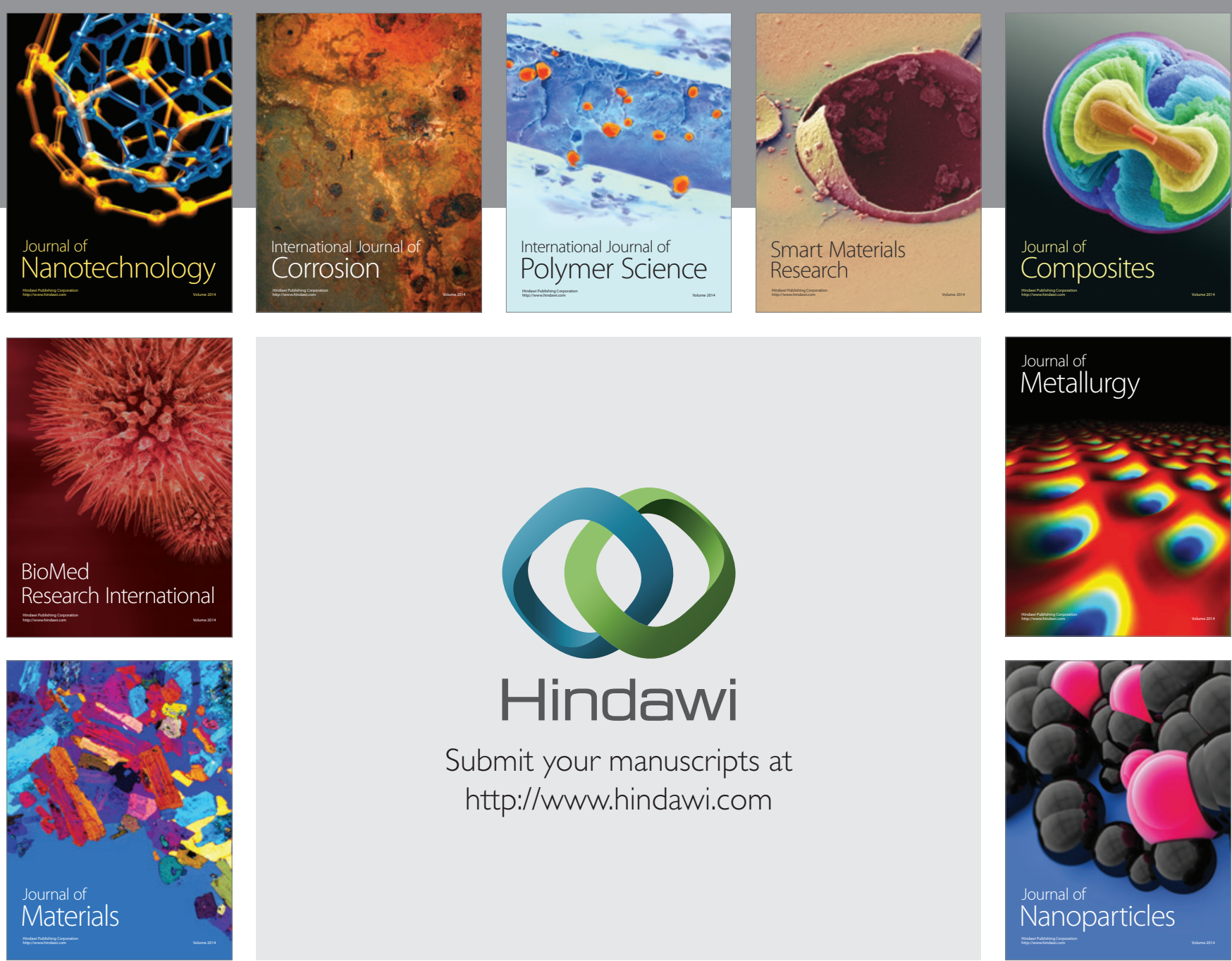

\section{Hindawi}

Submit your manuscripts at

http://www.hindawi.com

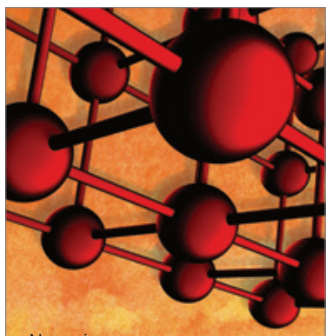

Materials Science and Engineering
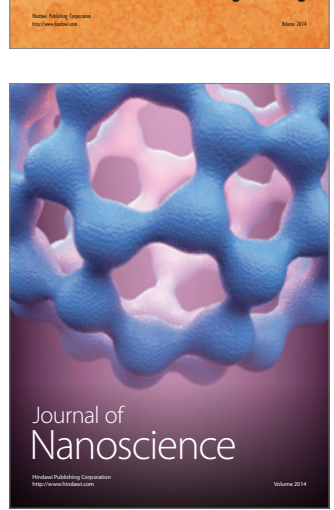
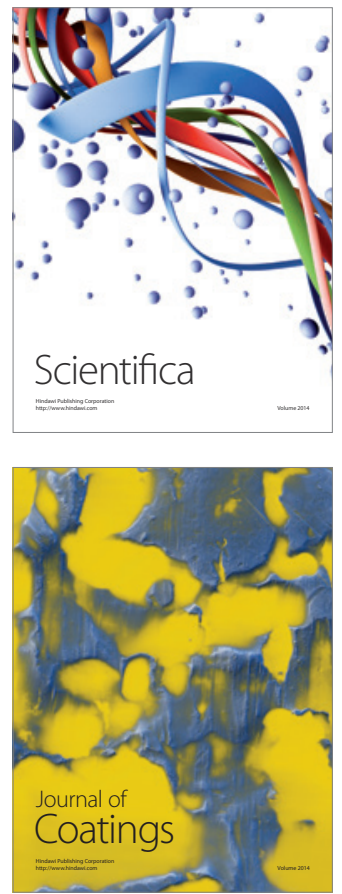
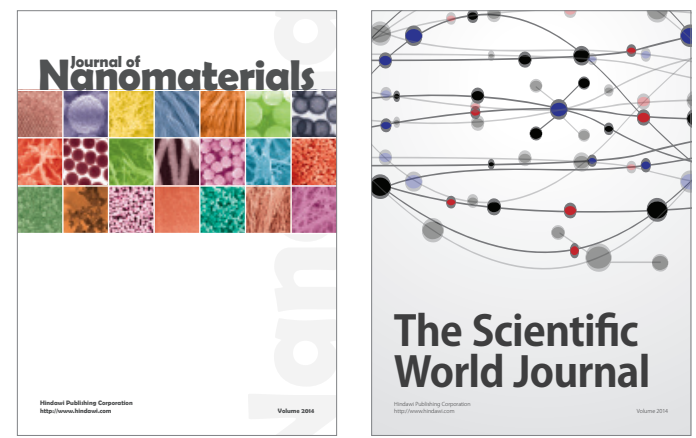

The Scientific World Journal
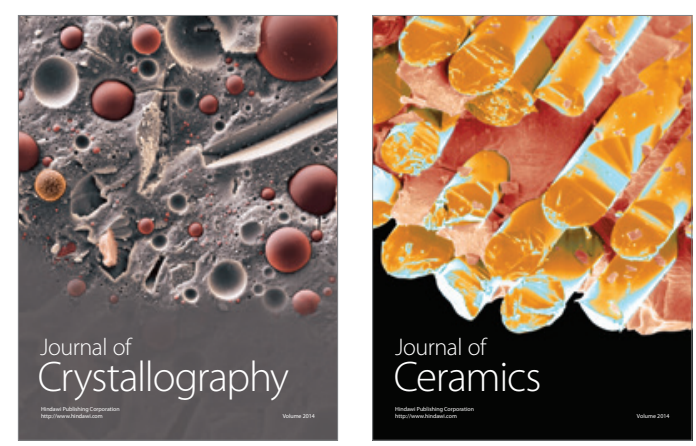
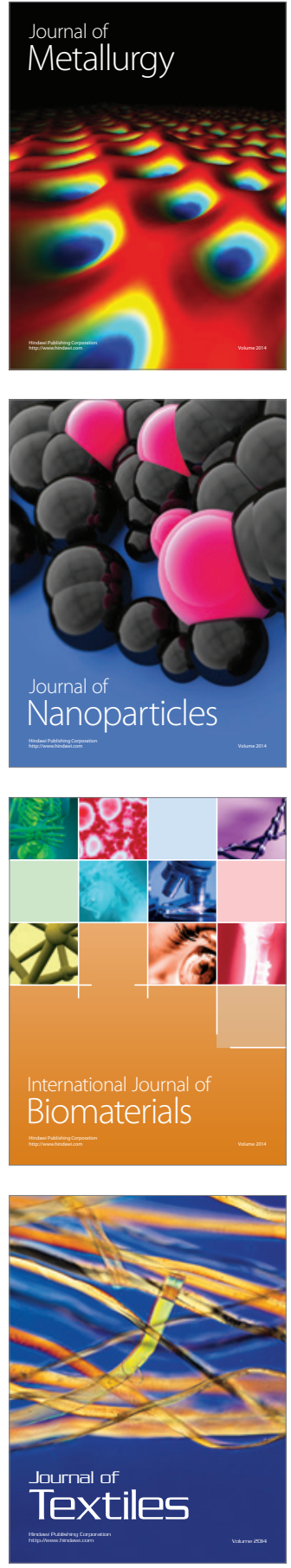